\title{
Pyk2 Signaling through Graf1 and RhoA GTPase Is Required for Amyloid- $\beta$ Oligomer-Triggered Synapse Loss
}

\author{
Suho Lee, Santiago V. Salazar, Timothy 0. Cox, and Stephen M. Strittmatter \\ Cellular Neuroscience, Neurodegeneration and Repair, Departments of Neurology and of Neuroscience, Yale University School of Medicine, New Haven, \\ Connecticut 06536
}

The intracellular tyrosine kinase Pyk2 (PTK2B) is related to focal adhesion kinase and localizes to postsynaptic sites in brain. Pyk2 genetic variation contributes to late onset Alzheimer's disease (AD) risk. We recently observed that Pyk2 is required for synapse loss and for learning deficits in a transgenic mouse model of AD. Here, we explore the cellular and biochemical basis for the action of Pyk 2 tyrosine kinase in amyloid- $\beta$ oligomer (A $\beta$ ) -induced dendritic spine loss. Overexpression of Pyk 2 reduces dendritic spine density of hippocampal neurons by a kinase-dependent mechanism. Biochemical isolation of Pyk2-interacting proteins from brain identifies Graflc, a RhoA GTPase-activating protein inhibited by Pyk2. A $\beta 0$-induced reductions in dendritic spine motility and chronic spine loss require both Pyk2 kinase and RhoA activation. Thus, Pyk2 functions at postsynaptic sites to modulate F-actin control by RhoA and regulate synapse maintenance of relevance to AD risk.

Key words: actin; Alzheimer; Graf1; PTK2B; Rho; synapse loss

\section{Significance Statement}

Genetic variation at the Pyk2 locus is a risk for Alzheimer's disease. We have observed that Pyk2 is required for AD transgenic synapse loss and memory dysfunction. However, the cellular and biochemical basis for Pyk2 function related to AD is not defined. Here, we show that brain Pyk2 interacts with the RhoGAP protein Graf1 to alter dendritic spine stability via RhoA GTPase. Amyloid- $\beta$ oligomer-induced dendritic spine loss requires the Pyk2/Grafl pathway.

\section{Introduction}

Synaptic maintenance and dendritic spine stability are crucial for brain function, such that dysregulation is thought to contribute to neurodegenerative disease. Therefore, intracellular signal networks regulating dendritic spine morphology are of high interest. Pyk2 (PTK2B, FAK2) is a tyrosine kinase closely similar to FAK (focal adhesion kinase; Mitra et al., 2005). FAK and Pyk2 are expressed in neurons with Pyk2 being most prominent in the brain (Zhang et al., 1994; Menegon et al., 1999). Pyk2 regulates synaptic plasticity, in particular long-term depression (Huang et al., 2001; Bartos et al., 2010; Hsin et al., 2010; Giralt et al., 2017; Salazar et al., 2018). The kinase activity of Pyk2 is activated by increased intracellular calcium, whereas another tyrosine kinase,

\footnotetext{
Received Nov. 25, 2018; revised Dec. 20, 2018; accepted Dec. 22, 2018.

Author contributions: S.L. wrote the first draft of the paper; S.L., S.V.S., T.O.C., and S.M.S. edited the paper; S.L. and S.M.S. designed research; S.L., S.V.S., and T.O.C. performed research; S.L., S.V.S., T.O.C., and S.M.S. analyzed data; S.L. and S.M.S. wrote the paper.

This work was supported by Grants from the Falk Medical Research Trust to S.M.S., and from the NIH to S.V.S. and S.M.S. We thank Stefano Sodi for expert technical assistance.

The authors declare no competing financial interests.

Correspondence should be addressed to Stephen M. Strittmatter at Stephen.Strittmatter@yale.edu.

https://doi.org/10.1523/JNEUROSCI.2983-18.2018

Copyright $\odot 2019$ the authors $\quad 0270-6474 / 19 / 391910-20 \$ 15.00 / 0$
}

Fyn, phosphorylates Pyk2 to achieve its full activation (Dikic et al., 1996; Qian et al., 1997; Andreev et al., 2001; H. J. Park et al., 2004; Collins et al., 2010a,b). Fyn and Pyk2 cross-activate one another, and function in a bidirectional synergistic manner (Dikic et al., 1996; Qian et al., 1997; Andreev et al., 2001; S. Y. Park et al., 2004; Collins et al., 2010a,b; Kaufman et al., 2015). Pyk2 genedeletion studies have not assessed dendritic spine stability or synaptic maintenance.

Alzheimer's disease $(\mathrm{AD})$ creates a massive human health burden, with $>5$ million individuals afflicted in the United States alone (Alzheimer's Association, 2012). Pyk2 (PTK2B) is a late onset AD (LOAD) risk gene (Lambert et al., 2013). Although $P y k 2$ gene alters AD risk, the mechanism(s) relevant to AD accumulation of either amyloid- $\beta(\mathrm{A} \beta)$ or Tau proteins has not been defined. A Drosophila Pyk2 homolog contributes to neurodegeneration driven by mutant Tau protein (Dourlen et al., 2017), and Pyk2 binds to Tau (Li and Götz, 2018). With regard to $\mathrm{A} \beta$ pathology in $\mathrm{AD}$, our studies indicate that Pyk2 is activated after $\mathrm{A} \beta$ oligomer $(\mathrm{A} \beta \mathrm{o})$ binding to $\operatorname{PrP}^{\mathrm{C}}$, which engages mGluR5 signaling to activate Fyn kinase and Pyk2 kinase (Laurén et al., 2009; Gimbel et al., 2010; Um et al., 2012, 2013; Kaufman et al., 2015; Haas et al., 2016; Kostylev et al., 2018). Although this pathway is not essential in certain experimental Alzheimer models, the role 
of $\operatorname{PrP}^{\mathrm{C}}, \mathrm{mGluR} 5$, and Fyn is required for AD-related phenotypes in multiple studies using both pharmacological and genetic tools (for review, see Salazar and Strittmatter, 2017; Purro et al., 2018). The Pyk 2 homolog FAK is also activated by soluble $A \beta$ assemblies (Zhang et al., 1994). Transgenic AD mice with $A \beta$ accumulation exhibit Pyk2 activation. Furthermore, the elevated Pyk2 activity is normalized by $\operatorname{PrP}^{\mathrm{C}}$ deletion, by mGluR5 deletion or inhibition, or by Fyn inhibition, and this correction is coincident with restoration of synapse density (Kaufman et al., 2015; Haas and Strittmatter, 2016; Haas et al., 2016, 2017). We recently showed that Pyk2 is required for $A \beta$ o-induced suppression of hippocampal long-term potentiation, and for APPswe/PS1 $\Delta \mathrm{E} 9$ transgenic synapse loss and memory impairment (Salazar et al., 2018). However, the cellular and biochemical basis for Pyk2 mediation of these $\mathrm{AD}$ phenotypes is not known.

Here, we sought to determine how Pyk2 might control synapse maintenance of relevance to AD. We find that Pyk2 activation reduces dendritic spine number. In brain, a major partner of Pyk2 is GTPase regulator associated with focal adhesion kinase-1 (Graf1), a RhoA GTPase activating protein (GAP) inhibited by Pyk2. The ability of $A \beta O$ to reduce dendritic spine motility, and to cause spine loss requires Pyk2 expression. Thus, the LOAD risk gene Pyk 2 is coupled to an $\mathrm{A} \beta$ o signaling pathway can function as a proximal mediator of synapse loss.

\section{Materials and Methods}

Animals

All mice were cared for by the Yale Animal Resource Center. Yale's institutional animal care and use committee approved all experiments. The $\mathrm{APP}_{\text {swe }} / \mathrm{PSEN} 1 \Delta \mathrm{E} 9$ mice on a C57BL/6J background were purchased from The Jackson Laboratory (RRID:MMRRC_034832-JAX; Jankowsky et al., 2003). Pyk2 ${ }^{-1-}$ mice (Okigaki et al., 2003; RRID:MGI:3584536) on the C57BL6J background after 10 backcrosses were generously provided by Dr. David Schlaepfer (UCSD). All experiments used littermate control mice with no preference for male or female mice.

\section{Plasmid DNA constructs}

Full-length wild-type (WT) Pyk2, K457A, PXXP1mut, PXXP2mut, $\triangle \mathrm{PRD}$, and PRD mutants were subcloned into AAV-CAG-GFP vector (gift from K. Svoboda, Janelia Research Campus; Addgene, plasmid \#28014; RRID:Addgene_28014) for GFP tagging on N-terminus, AAVCAG-tagRFP vector, modified from AAV-CAG-GFP by replacing the GFP with tagRFP for tagRFP tagging on $\mathrm{N}$-terminus, or PcDNA3 with or without HA tag. Human Grafla and Graflc isoforms were generated from Graflb isoform (DNASU plasmid repository, clone ID HsCD00639889) by PCR, subcloned into AAV-CAG-tagRFP, pcDNA3, or pGEX6P-1. pRK5-MycRhoA-wt and pRK5-Myc-RhoA-T19N were gift from Gary Bokoch (Addgene, plasmid \#12962 and \#12963; RRID:Addgene_12962 and RRID: Addgene_12963). GFP and tagRFP expression plasmids were generated from AAV-CAG-GFP and AAV-CAG-tagRFP vector by the insertion of stop codon after GFP or tagRFP open reading frame (ORF). The myristoyl-GFP plasmid has been described previously (Um et al., 2012). Graf1 shRNA was designed from mouse Grafl sequence targeting 5'atgatgtaccagtttcaaa (1392-1441) site and cloned into the pAAV-U6-GFP vector (Cell Biolabs).

\section{Culture and transfection of mouse hippocampus neurons}

Cultured hippocampal neurons were prepared from embryonic day 17 fetal C57BL/6J mice. Briefly, dissected hippocampi were dissociated with papain and plated on poly-D-lysine-coated $18 \mathrm{~mm}$ glass coverslips or culture plates with plating medium (Neurobasal-A medium supplemented with 2\% B-27, 2\% FBS, 1\% GlutaMax, and 1 mm sodium pyruvate; all from ThermoFisher Scientific). Four hours after plating, all medium was replaced with FBS free culture medium (Neurobasal-A medium supplemented with 2\% B-27, 1\% GlutaMax, and $1 \mathrm{~mm}$ sodium pyruvate) and then $50 \%$ replacement every $7 \mathrm{~d}$. Neurons were transfected before plating by Amaxa Nucleofector (shRNA efficiency test) or at 17
DIV by modified calcium-phosphate method (Chang and De Camilli, 2001). Briefly, $7 \mu \mathrm{g}$ of plasmid DNA and $9 \mu \mathrm{l}$ of $2 \mathrm{M} \mathrm{CaCl}_{2}$ were mixed in distilled water to a total volume of $75 \mu \mathrm{l}$, and the same volume of $2 \times \mathrm{BBS}$ (in mM: $50 \mathrm{BES}, 280 \mathrm{NaCl}$, and $1.5 \mathrm{Na}_{2} \mathrm{HPO}_{4}, \mathrm{pH} 7.1$ ) was added. Original cultured medium was completely replaced by transfection medium (MEM, 1\% GlutaMax, $1 \mathrm{~mm}$ sodium pyruvate, $0.6 \%$ glucose, and $10 \mathrm{~mm}$ HEPES, pH 7.65), and plasmid DNA mixture was added to the neurons in transfection medium. After incubation for $90 \mathrm{~min}$ in $5 \% \mathrm{CO}_{2}$ incubator, washed twice for $20 \mathrm{~min}$ with transfection medium, $\mathrm{pH} 7.35$, and then returned to the original culture medium.

\section{Hek293T cell culture and transfection}

Human embryonic kidney 293T (Hek293T; RRID:CVCL_QW54) cells were cultured in DMEM containing $10 \% \mathrm{FBS}$ at $5 \% \mathrm{CO}_{2}$ and $37^{\circ} \mathrm{C}$ incubator and transfected using Lipofectamine 3000 reagent (ThermoFisher Scientific).

\section{Immunoprecipitation}

Lysates from transfected Hek293T cells or mouse forebrains were extracted with modified radio immune precipitation assay (RIPA) buffer (1\% Triton X-100, $50 \mathrm{~mm}$ Tris, $150 \mathrm{~mm} \mathrm{NaCl}, 1 \mathrm{~mm}$ EDTA, protease inhibitor cocktail, Roche, and phosphatase inhibitor cocktail, Roche) and quantitated the protein concentration by BCA assay kit (ThermoFisher Scientific). One milligram of lysates and $1 \mu \mathrm{g}$ of appropriate antibody (anti-GFP antibody, ChromoTek, gta-20; RRID:AB_2631357; anti-Pyk2 antibody, Santa Cruz Biotechnology sc1515; RRID:AB_632286, anti-HA antibody, Covance, MMS-101P; RRID:AB_2314672) mixtures were incubated for $2 \mathrm{~h}$ at $4^{\circ} \mathrm{C}, 20 \mu \mathrm{l}$ protein $\mathrm{A} / \mathrm{G}$ agarose beads (ThermoFisher Scientific) was added, and incubation continued for $1 \mathrm{~h}$ on rotator. The immunoprecipitated complexes were washed three times with RIPA buffer, eluted in SDS-PAGE sample-loading buffer from beads, and then resolved by SDS-PAGE and immunoblotted.

\section{Immunoblotting}

Proteins were resolved using precast $4-20 \%$ tris-glycine gels (Bio-Rad) and transferred to nitrocellulose membrane by iBlot Gel Transfer Device (ThermoFisher Scientific). The membranes were blocked in blocking buffer (Rockland, MB-070-010) for fluorescent immunoblot for $1 \mathrm{~h}$ at room temperature (RT) and incubated overnight in primary antibodies at $4^{\circ} \mathrm{C}$. The following antibodies were used: rabbit anti-Pyk2 (Abcam, ab32571, 1:1000; RRID:AB_777566), mouse anti-Pyk2 (Santa Cruz Biotechnology, SC130077, 1:1000; RRID:AB_2174109), anti-phospho-Pyk2 (Y402; Abcam ab131543, 1:1000; RRID:AB_11157717), anti-GFP (Abcam ab13970, 1:5000; RRID:AB_300798), anti-Fyn (Santa Cruz Biotechnology, sc71133, 1:1000; RRID:AB_1123049), anti-phospho-SFK (Cell Signaling Technology, 6943, 1:1000; RRID:AB_10013641), anti-flag (Sigma-Aldrich, F3165, 1:1000; RRID:AB_259529), anti-Grafl (Abcam, ab137085, 1:1000), antiPSD-95 (Synaptic Systems, 124 002, 1:2000; RRID:AB_887760), anti-Actin (Sigma-Aldrich, A2066, 1:2000; RRID:AB_476693), anti-Myc (Cell Signaling Technology, 2276, 1:5000; RRID:AB_331783), anti-RhoA (Cytoskeleton ARH04, 1:1000; RRID:AB_2718698), and anti-pY (Cell Signaling Technology, 9411, 1:1000; RRID:AB_331228). After primary antibody incubation, the membranes were washed and applied appropriate secondary antibodies (Odyssey donkey anti-rabbit, anti-mouse, or anti-chicken IRDye 680 or 800 conjugates, LI-COR Biosciences) for $1 \mathrm{~h}$ at RT. The proteins were visualized using a LI-COR Odyssey infrared imaging system and quantified with Image Studio Lite software (RRID:SCR_013715).

\section{Immunocytochemistry}

Cultured neurons were fixed in $4 \%$ paraformaldehyde/4\% sucrose/PBS for $15 \mathrm{~min}$, permeabilized for $5 \mathrm{~min}$ in $0.25 \%$ Triton X-100/Tyrode's solution (in mM: $136 \mathrm{NaCl}, 2.5 \mathrm{KCl}, 2 \mathrm{CaCl}_{2}, 1.3 \mathrm{MgCl}_{2}, 10 \mathrm{Na}$-HEPES, $10 \mathrm{D}$-glucose, $\mathrm{pH} 7.3$ ) and then incubated in $10 \% \mathrm{BSA}$ for $30 \mathrm{~min}$ at $37^{\circ} \mathrm{C}$ for blocking. Primary antibodies (anti-PSD-95, Millipore, MAB1596, 1:1000; RRID:AB_2092365; anti-Pyk2, Abcam, ab32571, 1:1000; antiMyc Cell Signaling Technology, 2276, 1:2000) diluted in 3\% BSA/Tyrode's solution were incubated for $2 \mathrm{~h}$ at $37^{\circ} \mathrm{C}$. Then, appropriate secondary antibodies (AlexaFluor 488 or AlexaFluor 568-conjugated donkey anti-mouse IgG or anti-rabbit-IgG, ThermoFisher Scientific, 
1:1000) were diluted in 3\% BSA/Tyrode's solution and applied for 45 $\min$ at $37^{\circ} \mathrm{C}$.

\section{Pyk2 binding-protein identification}

Anti-GFP antibody captured immunoprecipitates from $1 \mathrm{mg}$ protein from GFP or GFP-Pyk2 expressed Hek293T cell lysates with or without 5 mg mouse brain lysate mixtures were separated by SDS-PAGE and silverstained using silver-staining kit (Pierce, 24600). Pyk2-specific binding proteins in mouse brain were excised from the stained gel and tryptic peptides were identified by LC-MS/MS analysis with Keck Proteomics Facility (Yale University).

\section{$A \beta_{1-42}$ preparation}

Synthesized $\mathrm{A} \beta_{1-42}$ peptide was obtained from Keck large scale Peptide Synthesis Facility (Yale University). $\mathrm{A} \beta_{1-42}$ oligomers ( $\mathrm{A} \beta \mathrm{o}$ ) were prepared in specially formulated glutamate-free F-12 to avoid direct stimulation of cultured neurons as described previously (Laurén et al., 2009). Concentration of $\mathrm{A} \beta \mathrm{o}$ are expressed in monomer equivalents, with $1 \mu \mathrm{M}$ total $\mathrm{A} \beta_{1-42}$ peptide corresponding to $\sim 10 \mathrm{~nm}$ oligomeric species (Laurén et al., 2009). Each new preparation of $A \beta O$ was confirmed to be $>95 \%$ high molecular weight soluble oligomers by size exclusion chromatography as described previously (Laurén et al., 2009; Um et al., 2012; Kaufman et al., 2015).

\section{Mouse brain tissue collection for PSD fractionation and biochemistry}

After rapid decapitation, whole forebrain or cortex and hippocampus were quickly dissected and homogenized in ice-cold Syn-PER reagent (ThermoFisher Scientific) containing complete protease inhibitor cocktail (Roche) and phosphatase inhibitor cocktail (Roche) with Teflon homogenizer. Homogenized brain extract was spun at $1000 \times g$ for $10 \mathrm{~min}$ to remove pelleted nuclear fraction (P1). Supernatant (S1) was centrifuged at $15,000 \times g$ for 15 min to collect the crude membrane pellet (P2). P2 was resuspended in HEPES-buffered sucrose [0.32 M sucrose, $4 \mathrm{~mm}$ HEPES, pH 7.4, complete protease inhibitor cocktail (Roche), phosphatase inhibitor cocktail (Roche)], and then spun at $15,000 \times g$ for $15 \mathrm{~min}$ to yield the washed crude synaptosomal fraction (P2'). Lysed resulting pellet by hypo-osmotic shock in cold $\mathrm{H}_{2} \mathrm{O}$ with protease and phosphatase cocktail inhibitor and homogenized again with Teflon homogenizer then rapidly adjust to $4 \mathrm{~mm}$ HEPES. After hypo-osmotic lysis, samples were spun at $25,000 \times g$ for 20 min to separate the supernatant (S3) and pellet (P3). The P3 suspension in HEPES-buffered sucrose was loaded onto a discontinuous sucrose gradient $(0.8-1-1.2 \mathrm{M}$ sucrose solution in $4 \mathrm{~mm}$ HEPES, $\mathrm{pH}$ 7.4), followed by centrifugation for $2 \mathrm{~h}$ at $150,000 \times g$. The synaptosome fraction between $1 \mathrm{M}$ and 1.2 sucrose layer was collected and adjusted to $4 \mathrm{ml}$ with $4 \mathrm{~mm}$ HEPES $\mathrm{pH} 7.4$, spun at 150,000 $\times \mathrm{g}$ for 30 min to yield the pellet (SPM). SPM was resuspended in lysis buffer (50 mM HEPES, 2 mм EDTA, 1\% Triton X-100, protease inhibitor cocktail, and phosphatase inhibitor cocktail) and incubated for $15 \mathrm{~min}$. The suspension was spun at $32,000 \times g$ for $20 \mathrm{~min}$. The resulting pellet was extracted again with $0.5 \%$ Triton X-100 lysis buffer for $15 \mathrm{~min}$, and spun again at $200,000 \times g$ for $1 \mathrm{~h}$. Resulting pellet (PSD) was analyzed by immunoblot.

\section{RBD pull-down assay}

GST tagged Rhotekin RBD (GST-RBD) expression plasmid was transformed into BL-21 (DE3) Escherichia coli (Agilent) and the cells were cultured in $2 \times$ YT medium with ampicillin until $\mathrm{OD}_{600}$ reached 0.6 at $37^{\circ} \mathrm{C}$, and then protein expression was induced with $0.5 \mathrm{~mm} \mathrm{IPTG}$ for $6 \mathrm{~h}$ at $25^{\circ} \mathrm{C}$. Protein expression-induced cells were lysed in lysis buffer $(1 \%$ Triton X-100, $150 \mathrm{~mm} \mathrm{NaCl}, 20 \mathrm{~mm}$ Tris pH7.4, $1 \mathrm{~mm} \mathrm{MgCl}_{2}, 1 \mathrm{~mm}$ EGTA, $1 \mathrm{~mm}$ PMSF) with sonication and centrifuged at 20,000 $\times g$ for 15 $\min$ at $4^{\circ} \mathrm{C}$. Supernatant was incubated with Glutathione Sepharose $4 \mathrm{~B}$ beads (GE Healthcare) for $1 \mathrm{~h}$. GST-RBD immobilized beads were applied to lysates from transfected Hek293T cells or mouse brain lysates (lysis buffer: $1 \%$ Triton X-100, $150 \mathrm{~mm} \mathrm{NaCl}, 50 \mathrm{~mm}$ Tris pH7.4, $10 \mathrm{~mm}$ $\mathrm{MgCl}_{2}$, protease inhibitor cocktail (Roche), and phosphatase inhibitor cocktail (Roche), incubated for $1 \mathrm{~h}$ at $4^{\circ} \mathrm{C}$ and then analyzed by SDSPAGE and immunoblotting.

\section{Image acquisition and analysis of dendritic spine density}

GFP, GFP-Pyk2, and GFP-K457A transfected neurons were fixed at 21 DIV. In some experiments, GFP-Pyk2 expressed neurons were incubated immediately in $1 \mu \mathrm{M}$ PF-719 after transfection. For A $\beta$ o-induced spine loss experiments, $\mathrm{A} \beta \mathrm{o}$ ( $1 \mu \mathrm{m}$ monomer, $10 \mathrm{nM}$ oligomer estimate) or Vehicle (Veh) were applied to GFP, GFP-Pyk2-PRD, and GFP with MycRhoA-T19N expressed neurons at 17 DIV and replaced 50\% culture medium with fresh $\mathrm{A} \beta \mathrm{o}$ or Veh included conditioned culture medium every $24 \mathrm{~h}$ for $4 \mathrm{~d}$. For $6 \mathrm{~h}$ incubation, $\mathrm{A} \beta$ o or Veh were applied to $21 \mathrm{DIV}$ neurons without media change. Neurons were fixed and imaged with a $40 \times$ objective oil lens on a Nikon Eclipse Ti Spinning Disk Confocal Microscope driven by Volocity software (PerkinElmer). Images were obtained as a $1 \mu \mathrm{m} Z$-stack with $0.5 \mu \mathrm{m}$ spacing using a 488 laser. All imaging and analyses were completed by an observer unaware of genotype or treatment group.

Spine density was analyzed by an automated method using Imaris (Bitplane; RRID:SCR_007370) software in maximum intensity projected 2D images. In Imaris Surpass mode, a new filament was created using the AutoPath mode of the FilamentTracer to define the dendrite with minor modifications from previous studies (Swanger et al., 2011). All filaments counted were devoid of crossing neurites or additional dendritic branch points between defined start and end points. For the automatic spine detection, the minimum spine end diameter and maximum spine length were set at 0.3 and $4 \mu \mathrm{m}$. Automatic thresholds were used for generating spine seed points and surface rendering. After generating the trace, a filter was applied to ensure all dendritic protrusions $<3 \mu \mathrm{m}^{2}$ were defined as spines. For each condition, 3 dendrites were measured for each neuron and 5-7 neurons were assessed per coverslip. Myc-RhoA-T19N and flagGraflc expression was confirmed by immunostaining with anti-Myc and anti-Flag antibodies for imaged dendrites. All imaging and analyses were completed by an observer unaware of Pyk 2 genotype or $\mathrm{A} \beta$ o treatment group.

\section{Image acquisition and analysis of Pyk2 localization in immunostained neurons}

After $\mathrm{A} \beta \mathrm{o}$ ( $1 \mu \mathrm{M}$ monomer, $10 \mathrm{~nm}$ oligomer estimate) or Veh treatment for $1 \mathrm{~h}, 6 \mathrm{~h}$, and $4 \mathrm{~d}, 21$ DIV low-density cultured neurons were immunostained with appropriate antibodies and imaged with a $60 \times$ oilimmersion lens on a same microscope as for dendritic spine imaging. Postsynaptic area was selected from PSD-95 images by a predefined computer script using a constant threshold value and then the average fluorescence intensity was measured for Pyk2 within each PSD-95-positive area using Volocity software. All imaging and analyses were completed by an observer unaware of genotype or treatment group.

\section{Image acquisition and analysis of live neurons}

To measure the dendritic spine motility, myristoylated-GFP-expressing 21 DIV neurons from WT or Pyk $2^{-1-}$ mice were incubated with $\mathrm{A} \beta \mathrm{o}(1$ $\mu \mathrm{M}$ monomer, $10 \mathrm{nM}$ oligomer estimate) or Veh for $24 \mathrm{~h}$ and mounted in a magnetic chamber (Live Cell Instrument, CM-B18-1) on the stage of a Nikon Eclipse Ti Spinning Disk Confocal Microscope. Time-lapse images were acquired for $5 \mathrm{~min}$ with 10 s intervals in Tyrode's solution using $60 \times$ objective lens driven Volocity software. Time-lapse images ( 31 time frames over $5 \mathrm{~min}$ ) were subjected to SD projection to visualize spine motility in single image and colorized with thermal scale using ImageJ software (NIH; RRID:SCR_002074). Quantitative measurements of spine motility by calculating the changed area at individual dendritic spines were conducted by using ImageJ software by an observer unaware of treatment group. Spine motility was monitored as changed area by subtracting thresholded, binarized individual images from the merged area for every $30 \mathrm{~s}$ time frame over $5 \mathrm{~min}$. In some experiments, $1 \mu \mathrm{M}$ PF-719 or $10 \mu \mathrm{M} \mathrm{Y-27632} \mathrm{were} \mathrm{applied} \mathrm{with} \mathrm{or} \mathrm{without} \mathrm{A} \beta$ o for $24 \mathrm{~h}$.

\section{Brain tissue collection}

Mice were killed and brains were dissected, divided at the midline into two hemispheres where one hemisphere was drop-fixed in $4 \%$ paraformaldehyde (PFA) for $24 \mathrm{~h}$. The other hemisphere was flash frozen and stored at $-80^{\circ} \mathrm{C}$. Following PFA fixation, brains were stored in PBS with $0.05 \%$ sodium azide. For immunostaining, brains were cut into $40 \mu \mathrm{m}$ coronal sections using a Leica WT1000S Vibratome. Sections were stored 
in PBS with $0.05 \%$ sodium azide at $4^{\circ} \mathrm{C}$ until staining. Dentate gyrus PSD-95-immunoreactive area was measured as described previously (Gimbel et al., 2010; Um et al., 2013; Salazar et al., 2018). Thioflavin-Spositive plaque burden was assessed in sections as percentage area occupied, and TBS-soluble $\mathrm{A} \beta \mathrm{o}$ was measured using immobilized $\operatorname{PrP}^{\mathrm{C}}$ capture (Kostylev et al., 2015).

\section{PF-719 synthesis}

The previously described PF-719 (Tse et al., 2012) small molecule was synthesized by Chinglu Pharmaceutical Research. They provided mass spectroscopy data with appropriate parent ions and NMR spectroscopy data confirming the structure of the compound with $\sim 95 \%$ purity. This was validated independently by our laboratory and confirmed the presence of the major peak with an appropriate $\mathrm{m} / \mathrm{z}$.

Protein purification for in vitro direct binding test, kinase assay, and RhoGAP assay

GFP, GFP-Pyk2, GFP-K457A, and GFP-PXXP2 $2_{\text {mut }}$ purification. Hek293T cells were transfected with GFP, GFP-Pyk2, GFP-K457A, or GFP$\mathrm{PXXP} 2$ mut using Lipofectamine 3000 then expressed for $48 \mathrm{~h}$. Lysates from transfected Hek293T cells were incubated with anti-GFP antibody trapped agarose beads (ChromoTek, GFP-Trap_A) for $2 \mathrm{~h}$ at $4^{\circ} \mathrm{C}$. The immunoprecipitated complexes were washed 3 times with RIPA buffer then replaced RIPA buffer with detergent-free assay buffer (50 mM Tris, $150 \mathrm{~mm} \mathrm{NaCl}, \mathrm{pH}$ 7.4). Immobilized proteins were eluted by $0.1 \mathrm{~mm}$ glycine- $\mathrm{HCl}, \mathrm{pH} 2.3$, for direct binding test or kept in $4^{\circ} \mathrm{C}$ for kinase assay buffer for RhoGAP assay. Protein concentration was examined by SDS PAGE and Coomassie blue staining with BSA standard.

Graf1c and Graflc-SH3 domain purification. GST, GST-Graf1c, or GST-Graf1c-SH3 domain (Graf1c, aa 558-686) expression plasmid were transformed into BL-21 (DE3) E. coli. Cells were cultured in $2 \times \mathrm{YT}$ medium with ampicillin until OD600 reached 0.6 at $37^{\circ} \mathrm{C}$, and then protein expression was induced with $0.5 \mathrm{~mm}$ IPTG for $6 \mathrm{~h}$ at $25^{\circ} \mathrm{C}$. Cells were lysed in lysis buffer ( $1 \%$ Triton X-100, $150 \mathrm{~mm} \mathrm{NaCl}, 20 \mathrm{~mm}$ Tris pH7.4, $1 \mathrm{~mm} \mathrm{MgCl}_{2}, 1 \mathrm{~mm}$ EGTA, $1 \mathrm{~mm}$ PMSF) with sonication and centrifuged at $20,000 \times g$ for $15 \mathrm{~min}$ at $4^{\circ} \mathrm{C}$. Supernatant was incubated with Glutathione Sepharose 4B beads (GE Healthcare) for $1 \mathrm{~h}$. GST tagged protein immobilized beads were washed three times with lysis buffer, and then kept in $4^{\circ} \mathrm{C}$ for binding test or washed two times more with cleavage buffer (50 mm Tris-HCl, pH7.4, $150 \mathrm{~mm} \mathrm{NaCl}, 1 \mathrm{~mm}$ EDTA) for on-column cleavage for kinase assay and RhoGAP assay. Eluted protein was concentrated using Amicon ultra- 0.5 centrifugal filter (Millipore-Sigma) and quantitated by SDS-PAGE and Coomassie blue staining with BSA standard.

\section{In vitro direct binding test}

One microgram of purified GFP-Pyk2 protein incubated with GST, GSTGraf1c, or GST-Graf1c-SH3 immobilized agarose beads in lysis buffer for $1 \mathrm{~h}$ at $4^{\circ} \mathrm{C}$. Beads and protein complexes were washed with lysis buffer three times and subjected to SDS-PAGE for Coomassie blue staining or immunoblotting with anti-GFP antibody.

\section{In vitro Pyk2 kinase assay}

One microgra of bead immobilized GFP, GFP-Pyk2, GFP-K457A, GFPPXXP 2 mut were incubated with or without $1 \mu \mathrm{g}$ Graflc, 2 mM ATP in 10 $\mu$ l kinase buffer (50 mм HEPES, $10 \mathrm{~mm} \mathrm{MgCl}_{2}, 1 \mathrm{~mm}$ DTT). Reactions were incubated at $24^{\circ} \mathrm{C}$ for $1 \mathrm{~h}$ and terminated by addition of SDS sample buffer and boiling. Proteins were subjected to SDS-PAGE and immunoblotting with indicated antibodies.

\section{In vitro Graflc RhoGAP assay}

The RhoGAP Assay Biochem kit \#BK105 (Cytoskeleton) was used to determine the relative GAP activity of Graflc with Pyk2 WT, Pyk2K457A, or Pyk2-PXXP2 ${ }_{\text {mut }}$, or Graf1c alone. Briefly, kinase reactive samples were mixed with recombinant RhoA-His, RhoA-His alone, or RhoA-His with Graflc. Reactions were combined with $1 \times$ reaction buffer in a 96-well plate on ice, and GTP was added to each well at a final concentration of $200 \mu \mathrm{M}$. The plate was shaken at $200 \mathrm{rpm}$ for $5 \mathrm{~s}$ and then incubated at $37^{\circ} \mathrm{C}$ for $20 \mathrm{~min}$. At the end of the reaction, $120 \mu \mathrm{l}$ of CytoPhos reagent was added to each well. The reactions were incubated for $10 \mathrm{~m}$ at RT and then the absorbance was read at $650 \mathrm{~nm}$ to measure the level of GTP hydrolysis using FlexStation Microplate Reader (Molecular Devices). Reactions containing $1 \times$ reaction buffer + CytoPhos reagent only were used as background controls.

\section{Quantification and statistical analysis}

One-way ANOVA with post hoc Tukey pairwise comparisons, repeatedmeasures ANOVA, and Student's $t$ test as specified in the figure legends were performed using GraphPad Prism v5.0d (RRID:SCR_002798) or SPSS Statistics v22 (RRID:SCR_002865). Mean \pm SEM and specific $n$ values are reported in each figure legend and in Table 1. Data are considered to be statistically significant if $p \leq 0.05$. The assumption of Gaussian distribution was checked using D'Agostino-Pearson omnibus test.

\section{Results}

\section{Pyk 2 overexpression induces spine loss in neurons}

To evaluate the potential consequences of Pyk 2 gain-of-function in $\mathrm{AD}$, we expressed Pyk2 in primary culture of mouse hippocampal neurons. We overexpressed GFP-Pyk2, or untagged Pyk2 (GFP and Pyk2), in neurons, and observed activation by autophosphorylation on residue Y402 (H. J. Park et al., 2004) and an expression pattern throughout dendrites (Fig. $1 A-C$ ). This expression led to a decrease in spine density by $60 \%$ compared with GFP-transfected neurons using an automated quantitation method (Fig. 1A,D). To test whether the kinase activity of Pyk2 was responsible for the observed spine loss, we pretreated GFPPyk2-expressing neurons with a specific small molecule inhibitor of Pyk2, PF-719 (Tse et al., 2012), and observed a rescue of GFPPyk2-induced spine loss. Concordantly, overexpressing the kinase inactive GFP-K457A mutant of Pyk2, at a level equal to WT GFP-Pyk2 (Fig. 1C), did not alter dendritic spine density compared with GFP-only transfected control (Fig. 1D). Thus, increased Pyk2 kinase activity induces synapse loss, consistent with Pyk2 activation contributing to synapse loss in $\mathrm{AD}$.

\section{Pyk2 interacts with Graf1c and localizes to postsynaptic sites}

To explore the molecular basis for Pyk2 action, we examined Pyk2 immunoprecipitates for interacting proteins. We added lysate from GFP and GFP-Pyk2-expressing Hek293T cells to mouse brain lysate before capture with immobilized anti-GFP antibody (Fig. 2A). The two most prominent silver-stained protein species from the brain pull-down other than GFP-Pyk2 were excised and analyzed by LC-MS/MS. We identified Fyn and calcineurin A from one band, and Graf1 from another band as Pyk2-intearcting proteins. The Graf1 is known to exhibit GAP activity for RhoA and Cdc42, and the Graf1 BAR domain suggests a membrane sculpting function in clathrin-independent endocytosis (Hildebrand et al., 1996; Taylor et al., 1999; Lundmark et al., 2008; Doherty et al., 2011; Fig. 2B). Our identification of Graf1 confirms the results of a survey of $10 \mathrm{SH} 3$ domains for Pyk2 interaction, and the coimmunoprecipitation of the two proteins (Ohba et al., 1998). Given the spine loss data described above (Fig. 1), we focused on Grafl and the Pyk2-Graf1 interaction. Graf1 is highly expressed in the heart, brain, and lung (Taylor et al., 1998) and exists in three splice variants (Lucken-Ardjomande Häsler et al., 2014). Therefore, we sought to determine whether Pyk2 has a preference for binding among Graf1 isoforms. By immunoprecipitation of GFP-Pyk2 from Hek293T cells, we observed interaction with all three isoforms, but detectable stronger binding to isoforms a and c (Fig. 2B). Graflc is the predominant species expressed in brain (Lucken-Ardjomande Häsler et al., 2014) and endogenous Graflc is the predominant Graf1 isoform to coimmunoprecipitate with endogenous Pyk2 (Fig. 2C). These data suggest that Pyk2 is an endogenous binding partner of Graf1c. 
Table 1. Statistical analysis details

\begin{tabular}{|c|c|c|c|c|c|c|c|c|c|c|c|}
\hline \multirow[b]{2}{*}{ Figure } & \multirow[b]{2}{*}{ Assay performed } & \multirow[b]{2}{*}{ Parameter } & \multicolumn{2}{|l|}{ Comparison WT vs HT } & \multicolumn{2}{|c|}{ Descriptive Statistics } & \multicolumn{5}{|l|}{ Statistical Analysis } \\
\hline & & & Independent variables & $n$ & Average & Error (SE or SD) & Statistical test & $F$ & DF & $\begin{array}{l}\text { ANOVAp } \\
\text { values }\end{array}$ & Significance \\
\hline \multirow[t]{5}{*}{$1 C$} & \multirow[t]{5}{*}{ Fluorescence imaging } & \multirow[t]{5}{*}{ GFP intensity, AFU } & GFP & GFP $=7$ coverslips & 7088 & 338.5 (SE) & \multirow{5}{*}{$\begin{array}{l}\text { One-way ANOVA; Turkey's } \\
\text { multiple-comparisons } \\
\text { test }\end{array}$} & \multirow[t]{5}{*}{24.63} & \multirow[t]{5}{*}{34} & \multirow[t]{5}{*}{$p<0.0001$} & $\begin{array}{l}p=0.9976 \text { for GFP-Pyk2 vs GFP-Pyk2 \& } \\
\text { PF719 }\end{array}$ \\
\hline & & & GFP-Pyk2 & GFP-Pyk2 = 7 coverslips & 3814 & 299.8 (SE) & & & & & $\begin{array}{l}p=0.9521 \text { for GFP-Pyk2 vs GFP-Pyk2- } \\
\text { K457A }\end{array}$ \\
\hline & & & GFP-Pyk2 \& PF-719 & $\begin{array}{l}\text { GFP-Pyk2 \& PF-719 = } 7 \text { cover- } \\
\quad \text { slips }\end{array}$ & 3680 & 341.4 (SE) & & & & & $\begin{array}{l}p=0.0003 \text { for GFP-Pyk2 vs GFP-Pyk2 \& } \\
\text { PF719 }\end{array}$ \\
\hline & & & GFP-Pyk2-K457A & $\begin{array}{l}\text { GFP-Pyk2-K457A = } 7 \text { cover- } \\
\text { slips }\end{array}$ & 3515 & 163.4 (SE) & & & & & $\begin{array}{l}p<0.0001 \text { for GFP-Pyk2 vs GFP-Pyk2 \& } \\
\text { PF719 }\end{array}$ \\
\hline & & & GFP \& Pyk2 & GFP \& Pyk2 $=7$ coverslips & 5104 & 305.6 (SE) & & & & & \\
\hline \multirow[t]{4}{*}{10} & \multirow[t]{4}{*}{ Fluorescence imaging } & \multirow[t]{4}{*}{$\begin{array}{l}\text { Spine density, } \\
\qquad \mu \mathrm{m}^{-1}\end{array}$} & $\begin{array}{l}\text { GFP } \\
\text { GFP-Pyk2 }\end{array}$ & $\begin{array}{l}\text { GFP }=7 \text { coverslips } \\
\text { GFP-Pyk2 }=7 \text { coverslips }\end{array}$ & $\begin{array}{l}0.445 \\
0.219\end{array}$ & $\begin{array}{l}0.023 \text { (SE) } \\
0.024 \text { (SE) }\end{array}$ & \multirow[t]{4}{*}{$\begin{array}{l}\text { One-way ANOVA; Turkey's } \\
\text { multiple-comparisons } \\
\text { test }\end{array}$} & \multirow[t]{4}{*}{22.4} & \multirow[t]{4}{*}{34} & \multirow[t]{4}{*}{$p<0.0001$} & $\begin{array}{l}p<0.0001 \text { for GFP vs GFP-Pyk } 2 \\
p=0.5611 \text { for GFP vs GFP-Pyk2 \& } \\
\text { PF719 }\end{array}$ \\
\hline & & & GFP-Pyk2 \& PF-719 & $\begin{array}{l}\text { GFP-Pyk2 \& PF-719 = } 7 \\
\quad \text { coverslips }\end{array}$ & 0.392 & 0.035 (SE) & & & & & $p=0.9978$ for GFP vs GFP-Pyk2-K457A \\
\hline & & & GFP-Pyk2-K457A & $\begin{array}{l}\text { GFP-Pyk2-K457A = } \\
\text { coverslips }\end{array}$ & 0.435 & 0.016 (SE) & & & & & $p<0.0001$ for GFP vs GFP \& Pyk2 \\
\hline & & & GFP \& Pyk2 & GFP \& Pyk2 = 7 coverslips & 0.202 & 0.021 (SE) & & & & & $\begin{array}{l}p=0.0003 \text { for GFP-Pyk2 vs GFP-Pyk2 \& } \\
\text { PF719 } \\
p<0.0001 \text { for GFP-Pyk2 vs GFP-Pyk2- } \\
\text { K457A }\end{array}$ \\
\hline \multirow[t]{4}{*}{$3 B$} & $\begin{array}{l}\text { Fluorescence imaging } \\
\text { and colocaliza- }\end{array}$ & Merged area, $\%$ & GFP \& RFP-Graf1C & GFP \& RFP-Graf1c $=11$ images & 20.03 & 8.255 (SD) & $\begin{array}{l}\text { One-way ANOVA; Turkey's } \\
\text { multiple-comparisons }\end{array}$ & 64.96 & 42 & $p<0.0001$ & $\begin{array}{l}p<0.0001 \text { for GFP \& RFP-Graf1c vs } \\
\text { GFP-Pyk2 \& RFP-Graf1c }\end{array}$ \\
\hline & tion test & & GFP-Pyk2 \& RFP-Graf1c & $\begin{array}{l}\text { GFP-Pyk2 \& RFP-Graf1c }=12 \\
\text { images }\end{array}$ & 86.76 & 18.02 (SD) & test & & & & $\begin{array}{c}p=0.1656 \text { for GFP \& RFP-Graf1c vs } \\
\text { GFP-PXXP2mut \& RFP-Grf1c }\end{array}$ \\
\hline & & & GFP-PXXP2 $2_{\text {mut }} \&$ RFP-Graf1c & $\begin{array}{l}\text { GFP-PXXP2 } 2_{\text {mut }} \& \text { RFP-Graf1c }= \\
10 \text { images }\end{array}$ & 32.81 & $11.4(S D)$ & & & & & \\
\hline & & & GFP-PSD95 \& RFP-Graf1c & $\begin{array}{l}\text { GFP-PSD95 \& RFP-Graf1C }=10 \\
\text { images }\end{array}$ & 80.99 & 15 (SD) & & & & & \\
\hline $4 B$ & Western blotting & $\begin{array}{l}\text { Graf1c/actin ratio, } \\
\text { normalized by } \\
\text { control }\end{array}$ & $\begin{array}{l}\text { Control } \\
\text { Graf1 shRNA }\end{array}$ & $\begin{array}{l}\text { Control }=5 \text { experiments } \\
\text { Graf1 shRNA }=5 \text { experiements }\end{array}$ & $\begin{array}{l}1 \\
0.579\end{array}$ & $\begin{array}{r}0(S D) \\
0.1753(S D)\end{array}$ & Student's two tailed $t$ test & & & & $p=0.0007$ for Control vs Graf1 shRNA \\
\hline 40 & ICC & & $\begin{array}{l}\text { Pyk2 intensity in synapse, } \\
\text { normalized to U6 Control }\end{array}$ & $\begin{array}{l}\text { Control }=22 \text { images } \\
\text { Graf1 shRNA }=21 \text { images }\end{array}$ & $\begin{array}{l}1 \\
0.736\end{array}$ & $\begin{array}{l}0.1035 \text { (SE) } \\
0.0597 \text { (SE) }\end{array}$ & Student's two tailed $t$ test & & & & $p=0.035$ for Control vs Graf1 shRNA \\
\hline & & & $\begin{array}{l}\text { Pyk2 intensity in ex-synapse, } \\
\text { normalized to U6 Control }\end{array}$ & $\begin{array}{l}\text { Control }=22 \text { images } \\
\text { Graf1 shRNA }=21 \text { images }\end{array}$ & $\begin{array}{l}1 \\
1.072\end{array}$ & $\begin{array}{l}0.0754 \text { (SE) } \\
0.0781 \text { (SE) }\end{array}$ & Student's two tailed $t$ test & & & & $p=0.2593$ for Control vs Graf1 shRNA \\
\hline & & & $\begin{array}{l}\text { PSD-95 puncta \# in GFP area, } \\
\text { normalized to U6 Control }\end{array}$ & $\begin{array}{l}\text { Control }=22 \text { images } \\
\text { Graf1 shRNA }=21 \text { images }\end{array}$ & $\begin{array}{l}1 \\
0.739\end{array}$ & $\begin{array}{r}0.075 \text { (SE) } \\
0.0668 \text { (SE) }\end{array}$ & Student's two tailed $t$ test & & & & $p=0.9549$ for Control vs Graf1 shRNA \\
\hline 46 & ICC & & $\begin{array}{l}\text { Pyk2 intensity in PSD-95 } \\
\text { area, normalized to GFP } \\
\text { Control }\end{array}$ & $\begin{array}{l}\text { GFP }=19 \text { images } \\
\text { GFP-PRD }=14 \text { images }\end{array}$ & $\begin{array}{l}1 \\
0.689\end{array}$ & $\begin{array}{l}0.1209 \text { (SE) } \\
0.0607 \text { (SE) }\end{array}$ & Student's two tailed $t$ test & & & & $p=0.0478$ for GFP vs GFP-PRD \\
\hline $5 B$ & ICC & $\begin{array}{l}\text { Pyk2 intensity in } \\
\text { PSD-95 }\end{array}$ & $1 \mathrm{~h}$ & $\begin{array}{l}\text { Veh }=11 \text { coverslips } \\
A \beta 0=10 \text { coverslips }\end{array}$ & $\begin{array}{l}1 \\
1.042\end{array}$ & $\begin{array}{l}0.1133 \text { (SE) } \\
0.0958 \text { (SE) }\end{array}$ & Student's two tailed $t$ test & & & & $p=0.7810$ for Veh vs $A \beta 0$ \\
\hline & & $\begin{array}{l}\text { puncta, nor- } \\
\text { malized by }\end{array}$ & $6 \mathrm{~h}$ & $\begin{array}{l}\text { Veh }=10 \text { coverslips } \\
\mathrm{A} \beta 0=9 \text { coverslips }\end{array}$ & $\begin{array}{l}1 \\
1.153\end{array}$ & $\begin{array}{l}0.0798 \text { (SE) } \\
0.1286 \text { (SE) }\end{array}$ & Student's two tailed $t$ test & & & & $p=0.3157$ for Veh vs $A \beta 0$ \\
\hline & & Veh & $24 \mathrm{~h}$ & $\begin{array}{l}\text { Veh }=9 \text { coverslips } \\
A \beta 0=10 \text { coverslips }\end{array}$ & $\begin{array}{l}1 \\
1.284\end{array}$ & $\begin{array}{l}0.1118 \text { (SE) } \\
0.0612 \text { (SE) }\end{array}$ & Student's two tailed $t$ test & & & & $p=0.0352$ for Veh vs $A \beta 0$ \\
\hline $5 C$ & ICC & $\begin{array}{l}\text { PSD-95 puncta \# } \\
\text { /Pyk2 inten- }\end{array}$ & $1 \mathrm{~h}$ & $\begin{array}{l}\text { Veh }=11 \text { coverslips } \\
A \beta 0=10 \text { coverslips }\end{array}$ & $\begin{array}{l}1 \\
1.031\end{array}$ & $\begin{array}{l}0.0553 \text { (SE) } \\
0.1098 \text { (SE) }\end{array}$ & Student's two tailed $t$ test & & & & $p=0.7969$ for Veh vs $A \beta 0$ \\
\hline & & $\begin{array}{l}\text { sity, normal- } \\
\text { ized by Veh }\end{array}$ & $6 \mathrm{~h}$ & $\begin{array}{l}\text { Veh }=10 \text { coverslips } \\
A \beta 0=9 \text { coverslips }\end{array}$ & $\begin{array}{l}1 \\
0.901\end{array}$ & $\begin{array}{l}0.0533 \text { (SE) } \\
0.1107 \text { (SE) }\end{array}$ & Student's two tailed $t$ test & & & & $p=0.4203$ for Veh vs $A \beta 0$ \\
\hline & & & $24 \mathrm{~h}$ & Veh $=9$ coverslips & 1 & 0.0704 (SE) & Student's two tailed $t$ test & & & & $p=0.0352$ for Veh vs $A \beta 0$ \\
\hline & & & & $A \beta 0=10$ coverslips & 0.815 & $0.0493(\mathrm{SE})$ & & & & & \\
\hline $5 E$ & Western blotting & Protein / PSD-95 & Graf1c/ PSD-95 & $W T=6$ mice & 1 & 0.0977 (SD) & Student's two tailed $t$ test & & & & $p=0.0281$ for WT vs APP/PS1 \\
\hline & & ratio at $6 \mathrm{mo}$, & & APP/PS1 $=6$ mice & 1.168 & 0.1276 (SD) & & & & & \\
\hline & & normalized by & Pyk2/PSD-95 & $\mathrm{WT}=6$ mice & 1 & 0.2251 (SD) & Student's two tailed $t$ test & & & & $p=0.9793$ for WT vs APP/PS1 \\
\hline & & WT & & APP/PS1 $=6$ mice & 1.003 & 0.1081 (SD) & & & & & \\
\hline & & & Fyn/PSD-95 & $\mathrm{WT}=6$ mice & 1 & $0.2381(S D)$ & Student's two tailed $t$ test & & & & $p=0.7231$ for WT vs APP/PS1 \\
\hline & & & & $\mathrm{APP} / \mathrm{PS} 1=6$ mice & 0.9489 & 0.2479 (SD) & & & & & \\
\hline $5 G$ & Western blotting & Protein/PSD-95 & Graf1c/ PSD-95 & Total_WT $=5$ mice & 1 & 0.1085 (SD) & & & & & \\
\hline & & ratio at $9 \mathrm{mo}$, & & Total_APP/PS1 = 5 mice & 1.033 & 0.0789 (SD) & & & & & \\
\hline & & normalized by & & PSD_WT $=5$ mice & 1 & 0.0595 (SD) & Student's two tailed $t$ test & & & & $p=0.0004$ for WT vs APP/PS1 \\
\hline & & WT & & PSD_APP/PS1 = 5 mice & 1.197 & 0.0458 (SD) & & & & & \\
\hline & & & Pyk2/PSD-95 & Total_WT $=5$ mice & 1 & 0.1698 (SD) & & & & & \\
\hline & & & & Total_APP/PS1 $=5$ mice & 0.984 & 0.0794 (SD) & & & & & \\
\hline & & & & PSD_WT $=5$ mice & 1 & 0.2054 (SD) & Student's two tailed $t$ test & & & & $p=0.0022$ for WT vs APP $/$ PS1 \\
\hline & & & & PSD_APP/PS1 $=5$ mice & 1.565 & 0.1971 (SD) & & & & & \\
\hline & & & Fyn / PSD-95 & Total_WT $=5$ mice & 1 & 0.1317 (SD) & & & & & \\
\hline & & & & Total_APP/PS1 $=5$ mice & 1.071 & 0.0856 (SD) & & & & & \\
\hline & & & & PSD_WT $=5$ mice & 1 & 0.1182 (SD) & Student's two tailed $t$ test & & & & $p=0.5068$ for WT vs APP/PS1 \\
\hline & & & & PSD_APP/PS1 $=5$ mice & 1.071 & 0.1965 (SD) & & & & & \\
\hline
\end{tabular}


Table 1. Continued

\begin{tabular}{|c|c|c|c|c|c|c|c|c|c|c|c|}
\hline \multirow[b]{2}{*}{ Figure } & \multirow[b]{2}{*}{ Assay performed } & \multirow[b]{2}{*}{ Parameter } & \multicolumn{2}{|l|}{ Comparison WT vs HT } & \multicolumn{2}{|c|}{ Descriptive Statistics } & \multicolumn{5}{|l|}{ Statistical Analysis } \\
\hline & & & Independent variables & $n$ & Average & Error (SE or SD) & Statistical test & $F$ & DF & $\begin{array}{l}\text { ANOVA } p \\
\text { values }\end{array}$ & Significance \\
\hline \multirow[t]{6}{*}{$5 l$} & Western Blotting & Protein/PSD-95 & Graf1c/ PSD-95 & PSD_WT $=6$ mice & 1 & 0.0419 (SD) & ) Student's two tailed $t$ test & & & & $p=0.0411$ for WT vs APP/PS1 \\
\hline & & ratio at 13 & & PSD_APP/PS1 $=6$ mice & 1.143 & $0.0445(S D)$ & & & & & \\
\hline & & mo, normal- & Pyk2 / PSD-95 & PSD_WT = 6 mice & 1 & 0.0442 (SD) & ) Student's two tailed $t$ test & & & & $p=0.0128$ for WT vs APP/PS1 \\
\hline & & ized by WT & & PSD_APP/PS1 $=6$ mice & 1.326 & 0.0981 (SD) & & & & & \\
\hline & & & Fyn / PSD-95 & PSD_WT $=6$ mice & 1 & 0.0489 (SD) & ) Student's two tailed $t$ test & & & & $p=0.9337$ for WT vs APP/PS1 \\
\hline & & & & PSD_APP/PS1 $=6$ mice & 1.009 & $0.088(S D)$ & & & & & \\
\hline \multirow[t]{6}{*}{5} & PLISA & $\begin{array}{r}\mathrm{ng} A \beta 0, \mathrm{ng} / \\
\text { tissue, } \mathrm{g}\end{array}$ & WT, 3 mo & $\mathrm{WT}=6$ mice & 0.135 & 0.1343 (SE) & $\begin{array}{l}\text { One-way ANOVA; Turkey's } \\
\text { multiple-comparisons }\end{array}$ & 19.23 & 35 & $p<0.0001$ & $\begin{array}{l}p<0.0001 \text { for APP/PS1 } 3 \text { mo vs APP/ } \\
\text { PS1 } 12 \text { mo }\end{array}$ \\
\hline & & & APP/PS1, 3 mo & APP/PS1 = 6 mice & 0.4194 & 0.2721 (SE) & test & & & & $\begin{array}{l}p<0.0001 \text { for APP/PS1 } 6 \text { mo vs APP/ } \\
\text { PS1 } 12 \text { mo }\end{array}$ \\
\hline & & & APP/PS1, $6 \mathrm{mo}$ & $\mathrm{APP} / \mathrm{PS} 1=6$ mice & 1.237 & 0.6306 (SE) & & & & & $\begin{array}{l}p<0.0001 \text { for APP/PS1 } 9 \text { mo vs APP/ } \\
\text { PS1 } 12 \text { mo }\end{array}$ \\
\hline & & & APP/PS1, 9 mo & APP/PS1 $=6$ mice & 6.008 & 2.126 (SE) & & & & & \\
\hline & & & WT, 12 mo & APP/PS1 $=6$ mice & 0.354 & 0.0897 (SE) & & & & & \\
\hline & & & APP/PS1, $12 \mathrm{mo}$ & $\mathrm{APP} / \mathrm{PS} 1=6$ mice & 35.43 & 7.478 (SE) & & & & & \\
\hline \multirow[t]{6}{*}{$5 K$} & $\mathrm{IHC}$ & $\begin{array}{l}\text { Thioflavin S, \% } \\
\text { area }\end{array}$ & WT, 3 mo & $W T=8$ mice & 0.0001279 & $8.331 e-005$ (SE) & $\begin{array}{l}\text { One-way ANOVA; Turkey's } \\
\text { multiple-comparisons }\end{array}$ & 34.01 & 46 & $p<0.0001$ & $\begin{array}{l}p<0.0001 \text { for APP/PS1 } 3 \text { mo vs APP/ } \\
\text { PS1 } 12 \text { mo }\end{array}$ \\
\hline & & & APP/PS1, 3 mo mo & APP/PS1 = 8 mice & 0.0005608 & 0.0002712 (SE) & test & & & & $\begin{array}{l}p<0.0001 \text { for APP/PS } 16 \text { mo vs APP/ } \\
\quad \text { PS1 } 12 \text { mo }\end{array}$ \\
\hline & & & APP/PS1, 6 mo & APP/PS1 $=8$ mice & 0.07512 & 0.02726 (SE) & & & & & $\begin{array}{l}p<0.0001 \text { for APP/PS1 } 9 \text { mo vs APP/ } \\
\text { PS1 } 12 \text { mo }\end{array}$ \\
\hline & & & APP/PS1, 9 mo & APP/PS1 $=8$ mice & 0.573 & 0.1102 (SE) & & & & & \\
\hline & & & WT, 12 mo & APP/PS1 $=7$ mice & 0.003523 & 0.00183 (SE) & & & & & \\
\hline & & & APP/PS1, $12 \mathrm{mo}$ & $\mathrm{APP} / \mathrm{PS} 1=8$ mice & 1.436 & 0.2099 (SE) & & & & & \\
\hline $5 L$ & $\mathrm{IHC}$ & PSD-95, \% area & $12 \mathrm{mo}$ & $\begin{array}{l}\text { WT }=7 \text { mice } \\
\text { APP/PS1 }=8 \text { mice }\end{array}$ & $\begin{array}{l}4.19 \\
1.331\end{array}$ & $\begin{array}{l}0.5074 \text { (SE) } \\
0.3533 \text { (SE) }\end{array}$ & $\begin{array}{l}\text { One-way ANOVA; Turkey's } \\
\text { multiple-comparisons } \\
\text { test }\end{array}$ & 1.666 & 62 & $p=0.1368$ & $p=0.0389$ for WT vs APP/PS1 \\
\hline \multirow[t]{5}{*}{$6 B$} & $\begin{array}{l}\text { In vitro GTP hydrolysis } \\
\text { assay }\end{array}$ & $\begin{array}{l}\text { GTP hydrolysis, } \\
\text { normalized by }\end{array}$ & Rho & RhoA $=8$ experiments & 1 & 0 (SD) & $\begin{array}{l}\text { One-way ANOVA; Turkey's } \\
\text { multiple-comparisons }\end{array}$ & 11.92 & 39 & $p<0.0001$ & $\begin{aligned} p= & 0.0028 \text { for RhoA \& Graf1c vs RhoA, } \\
& \text { Graf1c \& GFP-Pyk2 }\end{aligned}$ \\
\hline & & RhoA only & RhoA, Graf1c & RhoA, Graf1c $=8$ experiments & 2.134 & 0.5146 (SD) & test & & & & $\begin{aligned} p= & 0.3415 \text { for RhoA \& Graf1c vs RhoA, } \\
& \text { Graf1c \& GFP-K457A }\end{aligned}$ \\
\hline & & & RhoA, GFP-Pyk2, Graf1c & $\begin{array}{l}\text { RhoA, GFP-Pyk2, Graf1c }=8 \\
\quad \text { experiments }\end{array}$ & 1.411 & 0.3605 (SD) & & & & & $\begin{aligned} p= & 0.6208 \text { for RhoA \& Graf1c vs RhoA, } \\
& \text { Graf1c \& GFP-PXXP2mut }\end{aligned}$ \\
\hline & & & RhoA, GFP-K457A, Graf1c & $\begin{array}{l}\text { RhoA, GFP-K457A, Graf1c }=8 \\
\quad \text { experiments }\end{array}$ & 1.791 & 0.2888 (SD) & & & & & \\
\hline & & & RhoA, GFP-PXXP2mut, Graf1c & $\begin{array}{l}\text { RhoA, GFP-PXXP2mut, Graf1c }=8 \\
\quad \text { experiments }\end{array}$ & 1.877 & 0.4246 (SD) & & & & & \\
\hline \multirow[t]{6}{*}{60} & RBD pull-down assay & RhoA-GTP/total & RhoA & RhoA $=3$ experiments & 1 & 0 (SD) & ) One-way ANOVA; Turkey's & 23.59 & 17 & $p<0.0001$ & $p=0.0089$ RhoA vs RhoA \& GFP-Pyk2 \\
\hline & & $\begin{array}{l}\text { RhoA, nor- } \\
\text { malized by }\end{array}$ & RhoA \& GFP-Pyk2 & $\begin{array}{l}\text { RhoA \& GFP-Pyk2 = } 3 \text { experi- } \\
\text { ments }\end{array}$ & 1.476 & 0.1363 (SD) & $\begin{array}{l}\text { multiple- compari- } \\
\text { sons test }\end{array}$ & & & & $p=0.0155$ RhoA vs RhoA \& Graf1c \\
\hline & & WT & RhoA \& Graf1c & RhoA \& Graf1c $=3$ experiments & 0.559 & 0.0917 (SD) & & & & & $\begin{aligned} p= & 0.0018 \text { RhoA \& Graf1c vs RhoA, } \\
& \text { GFP-Pyk2, Graf1c }\end{aligned}$ \\
\hline & & & RhoA, GFP-Pyk2, Graf1c & $\begin{array}{l}\text { RhoA, GFP-Pyk2, Graf1c }=3 \\
\quad \text { experiments }\end{array}$ & 1.142 & 0.1307 (SD) & & & & & $\begin{array}{l}p>0.0001 \text { RhoA \& Graf1c vs RhoA, } \\
\text { GFP-K457A, Graf1c }\end{array}$ \\
\hline & & & RhoA, GFP-K457A, Graf1c & $\begin{array}{l}\text { RhoA, GFP-K457A, Graf1c }=3 \\
\quad \text { experiments }\end{array}$ & 0.563 & 0.1812 (SD) & & & & & $\begin{aligned} p= & 0.9703 \text { RhoA \& Graf1c vs RhoA, } \\
& \text { GFP-PXXP2mut, Graf1c }\end{aligned}$ \\
\hline & & & RhoA, GFP-PXXP2mut, Graf1c & $\begin{array}{l}\text { RhoA, GFP-PXXP2mut, Graf1c }=3 \\
\quad \text { experiments }\end{array}$ & 0.641 & 0.1713 (SD) & & & & & \\
\hline \multirow[t]{4}{*}{$7 B$} & RBD pull-down assay & RhoA-GTP/total & WT & Veh $=4$ experiments & 1 & 0.1474 (SD) & ) One-way ANOVA; Turkey's & 15.53 & 15 & $p=0.0002$ & $p=0.0075$ WT veh vs WT A $\beta 0$ \\
\hline & & RhoA, nor- & & $A \beta 0=4$ experiments & 1.651 & 0.3115 (SD) & multiple- compari- & & & & \\
\hline & & malized by & Pyk2 $^{-1-}$ & Veh $=4$ experiments & 0.715 & 0.2195 (SD) & sons test & & & & $p=0.9985$ Pyk2 $^{-1-}$ veh vs Pyk2 $2^{-l-}$ \\
\hline & & WT & & $A \beta 0=4$ experiments & 0.689 & 0.1985 (SD) & & & & & $A \beta 0$ \\
\hline \multirow[t]{6}{*}{$7 D$} & RBD pull-down assay & RhoA-GTP/total & $6 \mathrm{mo}$ & $W T=6$ mice & 1 & 0.5115 (SD) & Student's two tailed $t$ test & & & & $p=0.9534$ for WT vs APP/PS1 \\
\hline & & RhoA, nor- & & APP/PS1 $=6$ mice & 0.986 & 0.1899 (SD) & & & & & \\
\hline & & malized by & $9 \mathrm{mo}$ & $\mathrm{WT}=6$ mice & 1 & 0.1688 (SD) & ) Student's two tailed $t$ test & & & & $p=0.0027$ for WT vs APP/PS1 \\
\hline & & WT & & APP/PS1 $=6$ mice & 2.105 & 0.6613 (SD) & & & & & \\
\hline & & & $13 \mathrm{mo}$ & $\mathrm{WT}=6$ mice & 1 & 0.3357 (SD) & Student's two tailed $t$ test & & & & $p<0.0001$ for WT vs APP/PS1 \\
\hline & & & & APP/PS1 $=6$ mice & 2.828 & 0.568 (SD) & & & & & \\
\hline \multirow[t]{8}{*}{$8 B$} & Fluorescence imaging & Spine density, & GFP & GFP $=7$ coverslips & 0.483 & 0.0152 (SE) & One-way ANOVA; Turkey's & 11.48 & 48 & $p<0.0001$ & $p=0.4065$ for GFP vs GFP \& Y27632 \\
\hline & and Spine density & $\mu \mathrm{m}^{-1}$ & GFP \& Y27632 & GFP \& Y27632 $=6$ coverslips & 0.412 & 0.0253 (SE) & multiple- compari- & & & & $p=0.6567$ for GFP vs GFP $\&$ RhoA-T19N \\
\hline & & & GFP \& RhoA-T19N & GFP \& RhoA-T19N $=6$ coverslips & 0.425 & 0.0311 (SE) & sons test & & & & $p<0.0001$ for GFP vs GFP-Pyk2 \\
\hline & & & GFP-Pyk2 & GFP-Pyk2 $=6$ coverslips & 0.213 & 0.0254 (SE) & & & & & $\begin{array}{l}p<0.0001 \text { for GFP-Pyk2 vs GFP-Pyk2 \& } \\
\quad Y 27632\end{array}$ \\
\hline & & & GFP-Pyk2 \& Y27632 & $\begin{array}{l}\text { GFP-Pyk2 \& Y27632 = } 7 \\
\quad \text { coverslips }\end{array}$ & 0.422 & 0.0279 (SE) & & & & & $\begin{array}{l}p<0.0001 \text { for GFP-Pyk2 vs GFP-Pyk2 \& } \\
\text { RhoAT19N }\end{array}$ \\
\hline & & & GFP-Pyk2 \& RhoA-T19N & $\begin{array}{l}\text { GFP-Pyk2 \& RhoA-T19N }=4 \\
\text { coverslips }\end{array}$ & 0.43 & 0.0302 (SE) & & & & & $\begin{array}{l}p<0.0001 \text { for GFP-Pyk2 vs GFP-Pyk2 \& } \\
\text { Graf1c }\end{array}$ \\
\hline & & & GFP-Pyk2 \& Graf1c & $\begin{array}{l}\text { GFP-Pyk2 \& RhoA-T19N = } 6 \\
\quad \text { coverslips }\end{array}$ & 0.447 & 0.0197 (SE) & & & & & $p=0.9117$ for GFP vs GFP-PXXP2mut \\
\hline & & & GFP-PXXP2mut & GFP-PXXP2mut $=7$ coverslips & 0.423 & 0.0164 (SE) & & & & & \\
\hline
\end{tabular}




\begin{tabular}{|c|c|c|c|c|c|c|c|c|c|c|c|}
\hline \multirow[b]{2}{*}{ Figure } & \multirow[b]{2}{*}{ Assay performed } & \multirow[b]{2}{*}{ Parameter } & \multicolumn{2}{|l|}{ Comparison WT vs HT } & \multicolumn{2}{|c|}{ Descriptive Statistics } & \multicolumn{5}{|l|}{ Statistical Analysis } \\
\hline & & & Independent variables & $n$ & Average & Error (SE or SD) & Statistical test & $F$ & DF & $\begin{array}{l}\text { ANOVA } p \\
\text { values }\end{array}$ & Significance \\
\hline \multirow[t]{4}{*}{$8 D$} & \multirow{4}{*}{$\begin{array}{l}\text { Fluorescence imaging } \\
\text { and Spine density }\end{array}$} & \multirow{4}{*}{$\begin{array}{l}\text { Spine density, } \\
\qquad \mu \mathrm{m}^{-1}\end{array}$} & Control & Control $=8$ coverslips & 0.466 & 0.0165 (SE) & \multirow{4}{*}{$\begin{array}{l}\text { One-way ANOVA; Turkey's } \\
\text { multiple-comparisons } \\
\text { test }\end{array}$} & \multirow[t]{4}{*}{23.81} & \multirow[t]{4}{*}{22} & \multirow[t]{16}{*}{$p<0.0001$} & $p<0.0001$ for Control vs Graf1 shRNA \\
\hline & & & Graf1 shRNA & Graf1 shRNA $=5$ coverslips & 0.234 & 0.0223 (SE) & & & & & $\begin{array}{l}p=0.0006 \text { for Graf1 shRNA vs Graf1 } \\
\text { shRNA \& Y27632 }\end{array}$ \\
\hline & & & Graf1 shRNA \& Y27632 & $\begin{array}{l}\text { Graf1 shRNA \& Y27632 = } 5 \\
\text { coverslips }\end{array}$ & 0.391 & 0.0227 (SE) & & & & & $\begin{array}{l}p<0.0001 \text { for Graf1 shRNA vs Graf1 } \\
\text { shRNA \& RhoA-T19N }\end{array}$ \\
\hline & & & Graf1 shRNA \& RhoA-T19N & $\begin{array}{l}\text { Graf1 shRNA \& RhoA-T19N = } 5 \\
\text { coverslips }\end{array}$ & 0.456 & 0.0269 (SE) & & & & & \\
\hline \multirow[t]{10}{*}{$9 B$} & \multirow{10}{*}{$\begin{array}{l}\text { Live fluorescence } \\
\text { imaging spine } \\
\text { motility }\end{array}$} & \multirow{10}{*}{$\begin{array}{l}\text { Changed area, } \\
\min ^{-1}, \%\end{array}$} & WT & Veh $=16$ coverslips & 26.81 & 0.943 (SE) & \multirow[t]{2}{*}{ Student's two tailed $t$ test } & & & & \multirow[t]{2}{*}{$p<0.0001$ for Veh vs $A \beta 0$} \\
\hline & & & & $A \beta 0=14$ coverslips & 20.39 & 0.9693 (SE) & & & & & \\
\hline & & & Pyk2 $^{-1-}$ & Veh $=14$ coverslips & 32.65 & 1.562 (SE) & \multirow[t]{2}{*}{ Student's two tailed $t$ test } & & & & \multirow[t]{2}{*}{$p=0.6913$ for Veh vs $A \beta 0$} \\
\hline & & & & $A \beta 0=14$ coverslips & 31.82 & 1.348 (SE) & & & & & \\
\hline & & & WT \& PF-719 & Veh $=17$ coverslips & 32.21 & 1.134 (SE) & \multirow[t]{2}{*}{ Student's two tailed $t$ test } & & & & \multirow[t]{2}{*}{$p=0.9965$ for Veh vs $A \beta 0$} \\
\hline & & & & $A \beta 0=16$ coverslips & 32.21 & 1.144 (SE) & & & & & \\
\hline & & & WT \& Pyk2-PRD & Veh $=6$ coverslips & 30.31 & 4.104 (SE) & \multirow[t]{2}{*}{ Student's two tailed $t$ test } & & & & \multirow[t]{2}{*}{$p=0.8334$ for Veh vs $A \beta 0$} \\
\hline & & & & $A \beta 0=6$ coverslips & 29.19 & 3.162 (SE) & & & & & \\
\hline & & & WT \& Y27632 & Veh $=15$ coverslips & 33.21 & 1.578 (SE) & \multirow[t]{2}{*}{ Student's two tailed $t$ test } & & & & $p=0.7427$ for Veh vs $A \beta 0$ \\
\hline & & & & $A \beta 0=11$ coverslips & 32.38 & 1.945 (SE) & & & & & \\
\hline $9 D$ & Live fluorescence & Changed area, & Con & Con $=6$ coverslips & 28.15 & 1.299 (SE) & Student's two tailed $t$ test & & & & $p<0.0001$ for Con vs CytoD \\
\hline & $\begin{array}{l}\text { imaging Spine } \\
\text { motility }\end{array}$ & $\min ^{-1}, \%$ & CytoD & CytoD $=6$ coverslips & 9.37 & 0.806 (SE) & & & & & \\
\hline $10 B$ & Fluorescence imaging & Spine density, & WT & Con $=8$ coverslips & 0.447 & $0.0233(\mathrm{SE})$ & One-way ANOVA; Turkey's & 6.43 & 37 & $p=0.0006$ & $p=0.0034$ for Con vs $A \beta 04 d$ \\
\hline & and Spine density & $\mu \mathrm{m}^{-1}$ & & Veh $6 \mathrm{~h}=7$ coverslips & 0.456 & 0.0198 (SE) & multiple-comparisons & & & & $p=0.0023$ for Veh $4 \mathrm{~d}$ vs $A \beta 04 d$ \\
\hline & & & & $A \beta 06 \mathrm{~h}=7$ coverslips & 0.402 & 0.0203 (SE) & test & & & & \\
\hline & & & & Veh $4 d=8$ coverslips & 0.455 & 0.0248 (SE) & & & & & \\
\hline & & & & $A \beta 04 d=8$ coverslips & 0.333 & 0.0163 (SE) & & & & & \\
\hline 100 & Fluorescence imaging & Spine density, & Pyk2 $^{-1-}$ & Control $=8$ coverslips & 0.439 & 0.0119 (SE) & One-way ANOVA; Turkey's & 0.2701 & 39 & $p=0.8952$ & $p=0.997$ for Veh $4 \mathrm{~d}$ vs $A \beta_{0} 4 \mathrm{~d}$ \\
\hline & \& Spine density & $\mu \mathrm{m}^{-1}$ & & Veh $6 \mathrm{~h}=8$ coverslips & 0.456 & 0.0228 (SE) & multiple-comparisons & & & & \\
\hline & & & & $A \beta 06 \mathrm{~h}=8$ coverslips & 0.429 & 0.0211 (SE) & test & & & & \\
\hline & & & & Veh $4 d=8$ coverslips & 0.454 & 0.0282 (SE) & & & & & \\
\hline & & & & $\mathrm{A} \beta 04 \mathrm{~d}=8$ coverslips & 0.44 & 0.0203 (SE) & & & & & \\
\hline $10 F$ & Fluorescence imaging & Spine density, & PF-719 & Con $=8$ coverslips & 0.442 & 0.0102 (SE) & One-way ANOVA; Turkey's & 0.3202 & 23 & $p=0.7295$ & $p=0.7998$ for Veh $4 \mathrm{~d}$ vs $A \beta_{0} 4 \mathrm{~d}$ \\
\hline & \& Spine density & $\mu \mathrm{m}^{-1}$ & & Veh $4 \mathrm{~d}=8$ coverslips & 0.44 & 0.0204 (SE) & multiple-comparisons & & & & \\
\hline & & & & $\mathrm{A} \beta 04 \mathrm{~d}=8$ coverslips & 0.426 & 0.0137 (SE) & test & & & & \\
\hline & & & Pyk2-PRD & Con $=5$ coverslips & 0.44 & 0.0238 (SE) & One-way ANOVA; Turkey's & 0.6194 & 14 & $p=0.5546$ & $p=0.7966$ for Veh $4 \mathrm{~d}$ vs $A \beta 04 d$ \\
\hline & & & & Veh $4 \mathrm{~d}=5$ coverslips & 0.427 & 0.0179 (SE) & multiple-comparisons & & & & \\
\hline & & & & $A \beta 04 d=5$ coverslips & 0.409 & 0.018 (SE) & test & & & & \\
\hline & & & RhoA-T19N & Con $=5$ coverslips & 0.425 & 0.0246 (SE) & One-way ANOVA; Turkey's & 0.4549 & 14 & $p=0.6450$ & $p=0.7974$ for Veh $4 d$ vs $A \beta_{0} 4 d$ \\
\hline & & & & Veh $4 d=5$ coverslips & 0.458 & 0.027 (SE) & multiple-comparisons & & & & \\
\hline & & & & $A \beta_{0} 4 d=5$ coverslips & 0.435 & 0.0234 (SE) & & & & & \\
\hline
\end{tabular}

This table delineates the numerical values, replicates, variance, and statistical tests for the data presented in the indicated figures.

Previous data showed that the proline-rich domain (PRD) of Pyk2 binds the isolated Graf1c SH3 domain (Ohba et al., 1998). To confirm this in the setting of full-length proteins, we performed an immunoprecipitation experiment with full-length Graflc and Pyk2 along with several Pyk2-PRD mutants in Hek293T cells (Fig. 2D). Pyk2 protein contains two separate PXXP motifs, so it is possible that Pyk2 interacts with Graf1c through one, both or none of the PXXP motifs. To explore this, we immunoprecipitated GFP from Hek293T cells expressing GFP-Pyk2 and the indicated mutants (Fig. 2D). We observed coimmunoprecipitation of Graf1c with full-length GFP-Pyk2 and GFP-PRD (aa 680 870, include both PXXP motifs), partial coimmunoprecipitation with GFP-PXXP1 $1_{\text {mut }}$, and very little to zero coimmunoprecipitation with GFP-PXXP2 ${ }_{\text {mut }}$, GFPPXXP1\& $2_{\text {mut }}$, or GFP- $\triangle$ PRD (Pyk2 with both PRD regions deleted). This indicates that Grafl interacts with both PXXP motifs but interacts more strongly with the second PXXP motif of Pyk2 (aa substitutions: P857A, P860A). To further examine the direct interaction of Pyk 2 and Graflc, we performed an in vitro binding assay with purified recombinant protein (Fig. 2E). We used a GST fusion protein with GST-Graf1c_Full, containing full-length Graf1c protein, and GST-Graf1_SH3 domain, containing only the Graf1 SH3 domain. We performed a GST pull-down with purified GFP-Pyk2 and GST-Graf1c_Full or GFP-Pyk2 and GSTGraf1_SH3 and observed a prominent band for GFP-Pyk2 by
Coomassie stain or immunoblotting with anti GFP antibody. These data demonstrate a direct and specific interaction between Pyk2 and Graflc the SH3 domains. In addition to the PRD regions of Pyk2, we sought to determine the ability of Graf1c to bind Pyk2 under different phosphorylation states (Fig. $2 F$ ). We found that Pyk2 is able to bind Graflc independently of Pyk2 phosphorylation status. Thus, Graf1c is an endogenous binding partner of Pyk2 and their interaction is mediated by the Pyk2 $\mathrm{PRD}$ region and the Graf1c $\mathrm{SH} 3$ domain.

To define the potential function of the Pyk2-Graf1c interaction, we first assessed their relative subcellular localization in neurons. We expressed XFP-tagged Pyk2 and Graf1c constructs in primary mouse hippocampal neurons (Fig. $3 A-C$ ). RFPGraflc coexpressed together with GFP (to visualize neuronal morphology) generates RFP-Graflc specific puncta with a synapse-like morphology. Coexpression of GFP-PSD-95 and RFP-Graflc confirmed that RFP-Graflc puncta are indeed in dendritic spines (Fig. $3 B, C$ ). In contrast, overexpressed GFPPyk2 displays a diffuse cellular pattern similar to that of RFP alone. The endogenous Pyk2 expression pattern is more punctate and not as diffuse as GFP-Pyk2, such that the RFP-Graf1c plus endogenous Pyk 2 colocalization pattern is very similar to the expression pattern of GFP-Pyk2 and RFP-Graf1c (Fig. 3D). Quantitatively, coexpression of GFP-Pyk2 and RFP-Graf1c yields near complete colocalization of the two proteins (Fig. $3 A, C$ ). 
A

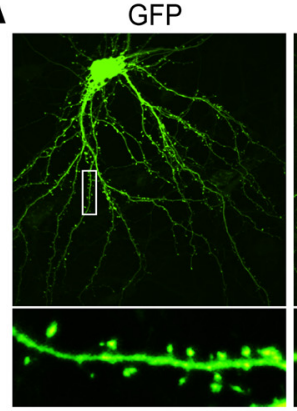

B

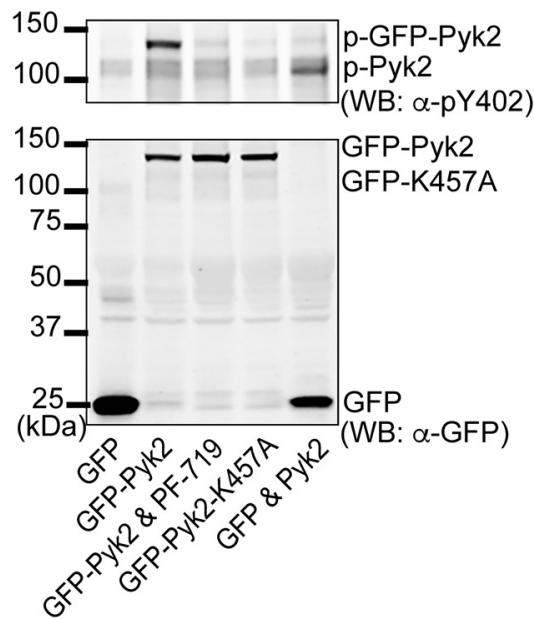

GFP-Pyk2

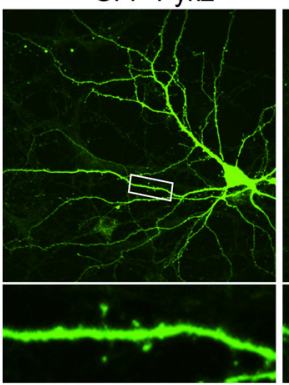

C

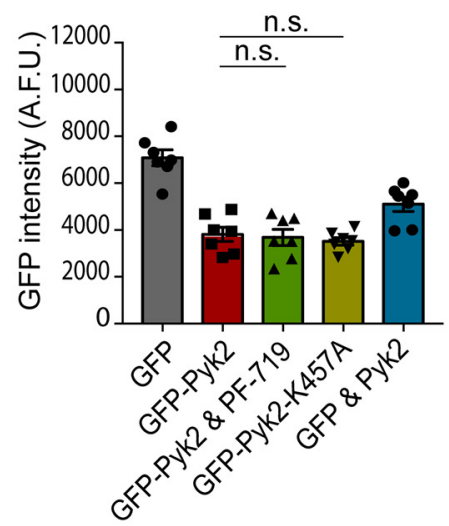

GFP-Pyk2 \& PF-719

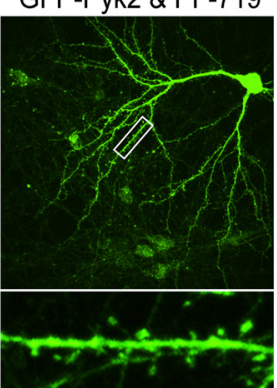

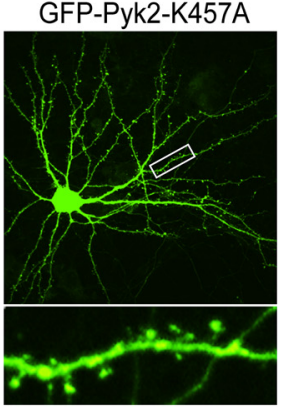

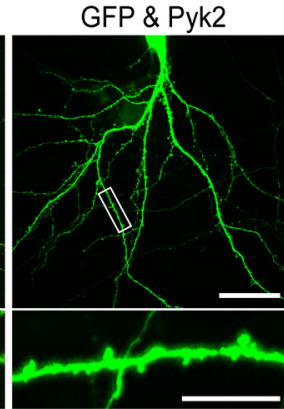

D
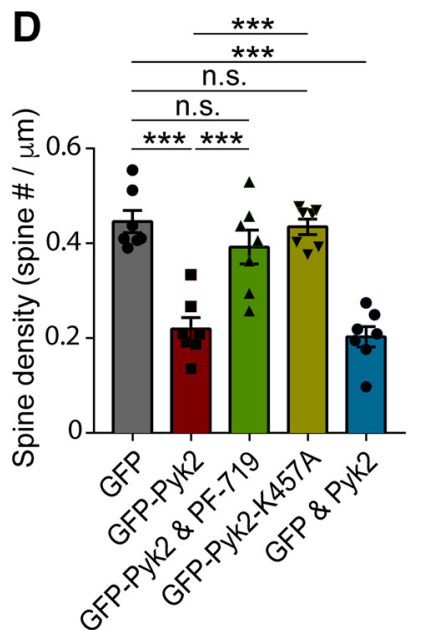

Figure 1. Pyk2 induces dendritic spine loss. A, Representative GFP fluorescent images of cultured mouse hippocampal neurons. Neurons were transfected with GFP alone, GFP-Pyk2, GFP-Pyk2 with $1 \mu \mathrm{M}$ PF-719, GFP-K457A, or GFP and Pyk2 (untagged) at DIV 14 and then fixed at 21 DIV. Bottom, Enlarged images of the enclosed rectangles on the top. Scale bars: low-magnification (top), $50 \mu \mathrm{m}$; high-magnification (bottom), $10 \mu \mathrm{m}$. B , Lysates from transfected neurons were subjected to Western blotting with anti-GFP and anti-p-Pyk2 Y402 antibodies. C, GFP intensity quantification from imaged neurons for spine quantitation in $\boldsymbol{A}$. $\boldsymbol{D}$, Quantification of dendritic spine density in the transfected neurons. Data are presented as mean \pm SEM (GFP, $n=10 ;$ GFP-Pyk2, $n=11$; GFP-Pyk2 and PF-719, $n=9$; GFP-K457A, $n=10$ coverslips from 3 different cultures). ${ }^{* * *} p<0.001$ by one-way ANOVA, Tukey's multiple-comparisons test.

Furthermore, this colocalization depends on the PRD region of Pyk2 because the colocalization is abolished with the Pyk2 PRD region mutant GFP-PXXP2 $2_{\text {mut }}$. Together, these data suggest that Pyk 2 and Graf1c associate and colocalize in the dendritic spines of neurons.

Given the dendritic spine colocalization of overexpressed Pyk2 and Graf1c, we sought to determine whether endogenous Pyk2 localization to synaptic structures requires Graf1c. We suppressed Graf1 expression by expressing a Graf1-targeting shRNA targeting all Graf1 isoforms (Fig. 4A,B). Primary mouse hippocampal neurons were visualized by coexpressed GFP (Fig. 4C). Colocalization of endogenous Pyk2 immunoreactivity within PSD-95-immunoreactive puncta significantly decreases in cells expressing Graf1 shRNA (Fig. 4C,D). This is consistent with Graf1c mediating Pyk2 colocalization at the synapse. To confirm this, we interrupted endogenous Pyk2 interaction with Graf1c by expression of a truncated GFP-PRD consisting of the isolated PRD region of Pyk2 (Fig. $4 E-G$ ). To verify the predicted dominant-negative function of the truncated fragment, we first coexpressed HA-Pyk2 together with Graf1c in Hek293T cells and immunoprecipitated HA-Pyk2 in the presence or absence of GFP-PRD. In a competitive manner, GFP-PRD blocks the HAPyk2 interaction with Graflc (Fig. 4E). When overexpressed in neurons, dominant-negative GFP-PRD significantly decreases the colocalization of endogenous Pyk2 (detected by an antibody recognizing a distinct epitope) with PSD-95 (Fig. 4F, G). Together, these data demonstrate that endogenous Pyk2 localiza- tion to PSD-95-positive dendritic spines requires the interaction of its PRD domain with Graflc.

Pyk2 enrichment at synapses is increased by $\mathrm{A} \beta \mathrm{\beta}$ signaling in neurons and APP/PS1 mice

We hypothesized that $\mathrm{AD}$ pathology and $\mathrm{A} \beta \mathrm{o}$ signaling might regulate the localization of Pyk2 at postsynaptic sites. We exposed primary hippocampal neurons to $\mathrm{A} \beta \mathrm{o}$ and determined the extent of endogenous Pyk2 immunoreactivity colocalizing with PSD-95 puncta. Treatment with $\mathrm{A} \beta \mathrm{o}$, but not vehicle, for $6 \mathrm{~h}$ induces a nonsignificant trend to increase Pyk2-PSD-95 colocalization, whereas $24 \mathrm{~h}$ exposure to $\mathrm{A} \beta \mathrm{o}$ significantly increases intensity of Pyk $2 \mathrm{immu}-$ noreactivity within PSD-95-immunoreactive puncta (Fig. 5A,B). This increase is not because of greater PSD-95 area, because the A $\beta$ o treatment decreases dendritic spine density (Um et al., 2012, 2013; Heiss et al., 2017; see three sections below), and the PSD-95 puncta count decreases in the same time period (Fig. 5C).

To assess the synaptic enrichment of Pyk2 in vivo, we measured both protein levels in postsynaptic density (PSD) preparations from WT and $\mathrm{APP}_{\text {swe }} / \mathrm{PSEN} 1 \Delta \mathrm{E} 9$ (hereafter referred to as APP/PS1; Jankowsky et al., 2004) mice at 6, 9, and 13 months of age (Fig. 5D-I). At 6 months of age, this strain has low levels of $\mathrm{A} \beta$ accumulation and no behavioral deficits or synaptic loss, whereas at 9 months of age, A $\beta$ o levels rise (Fig. $5 J$ ), plaque accumulates (Fig. $5 K$ ), synapses are lost (Fig. $5 L$ ), and memory function is impaired (Jankowsky et al., 2004; Janus et al., 2015; Hong et al., 2016). Pyk2 concentration in the PSDs of APP/PS1 
A

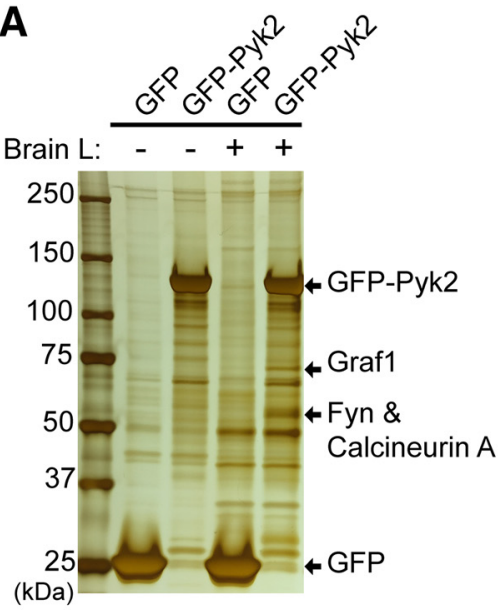

C

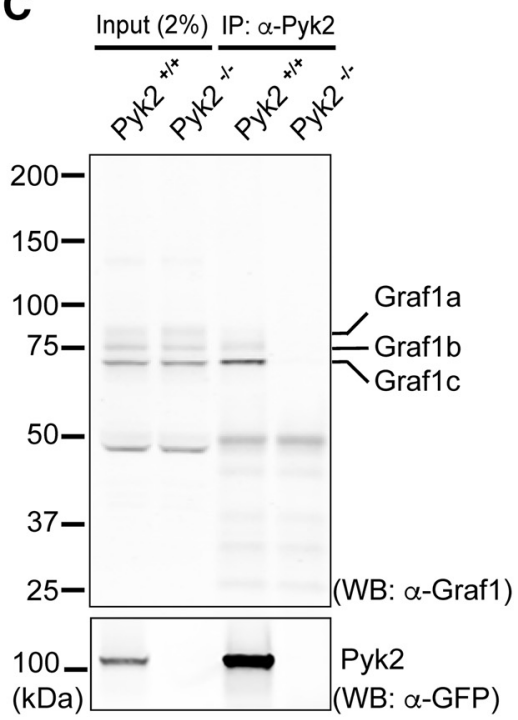

B
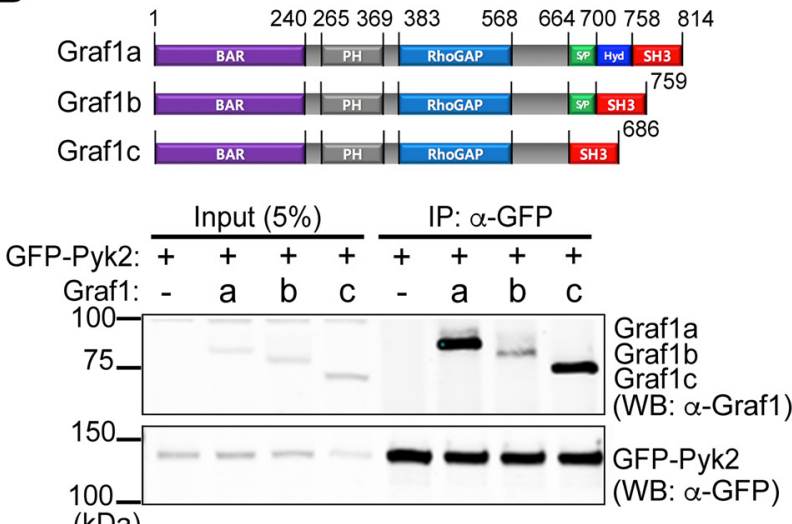

D

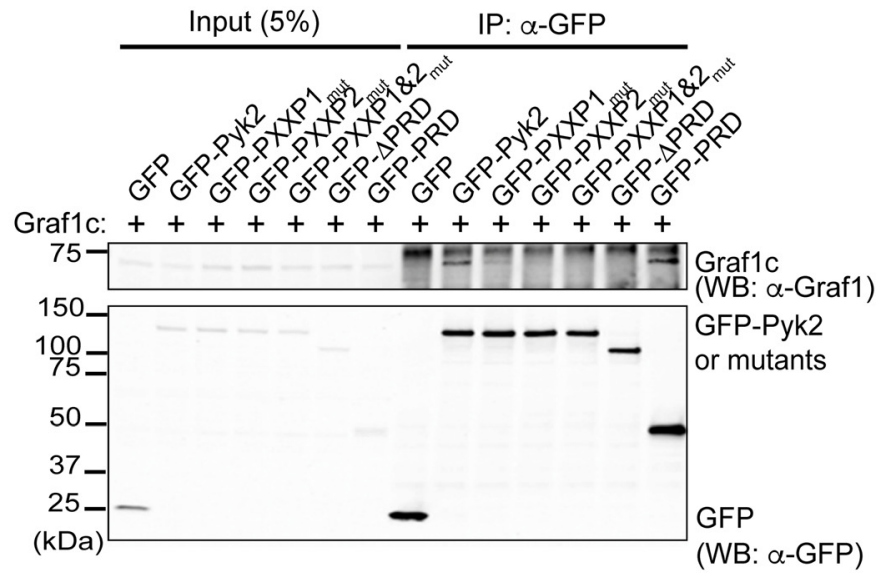

$\mathbf{F}$

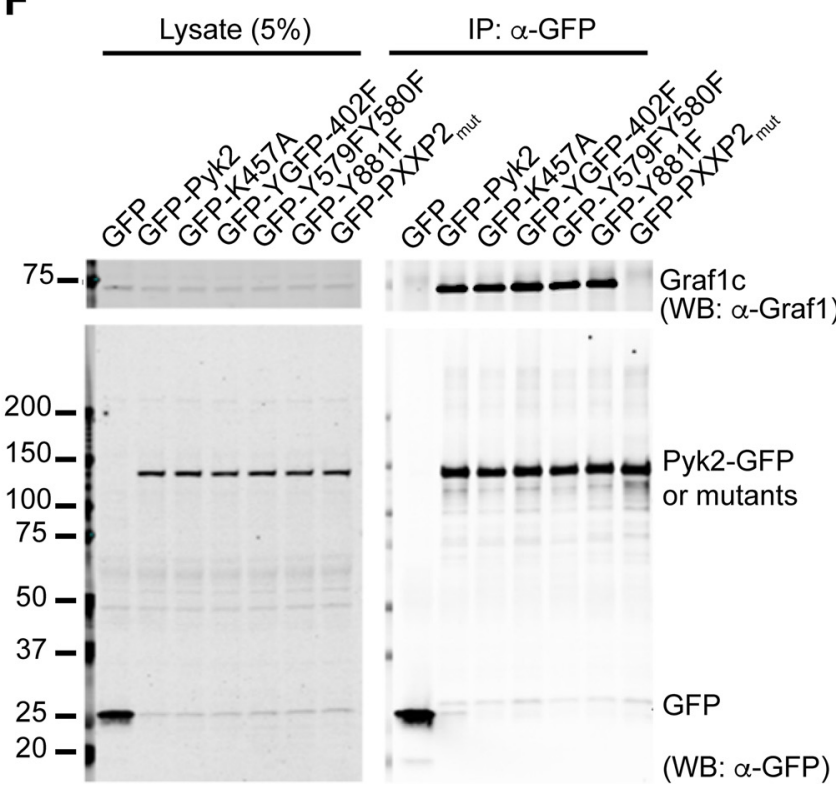

$(\mathrm{kDa})$

Figure 2. Graf1c interacts with Pyk2 and colocalizes to postsynaptic terminal. A, Lysates from GFP or GFP-Pyk2 transfected Hek293T cells or the same lysates mixed with mouse brain lysate (Brain L) were immunoprecipitated with anti-GFP antibody trapped agarose beads. The immunoprecipitates were separated by SDS-PAGE and silver stained to identify proteins for subsequent LC-MS/MS analysis. Three major binding proteins were identified as Graf1, Fyn, and calcineurin A. B, Graf1 isoforms domain structure diagrams and binding test in Pyk2 and Graf1 isoforms in overexpressed Hek293T cells. Pyk2 and Graf1 isoforms cotransfected Hek293T cell lysates were immunoprecipitated with anti-GFP antibody and immunoblotted with anti-Graf1 and anti-GFP antibodies. C, WT $\left(\right.$ Pyk2 ${ }^{+/+}$) and Pyk2 $\mathrm{KO}^{\left(P y k 2^{-I-}\right.}$ ) mouse brain lysates were immunoprecipitated with anti-Pyk2 antibody and immunoblotted with anti-Graf1 and anti-Pyk2 antibodies. (Figure legend continues.) 
A
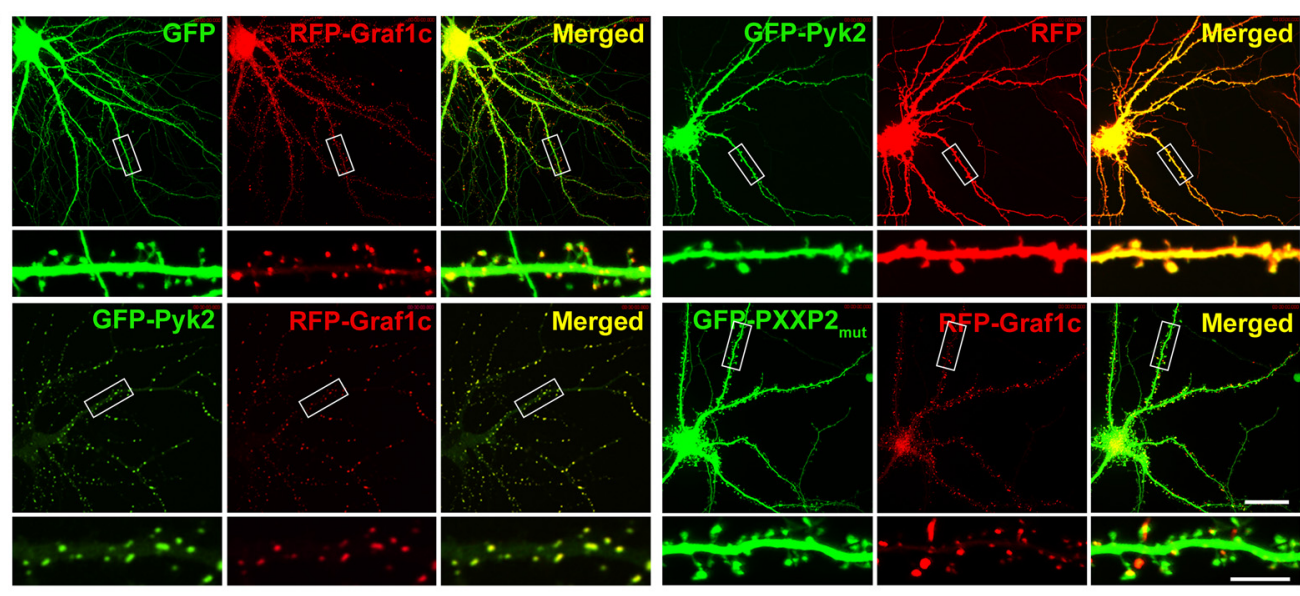

B
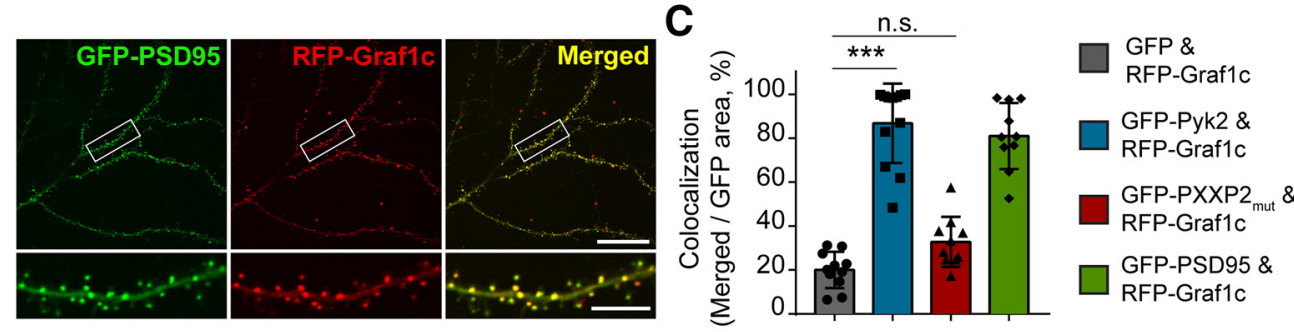

\section{D}
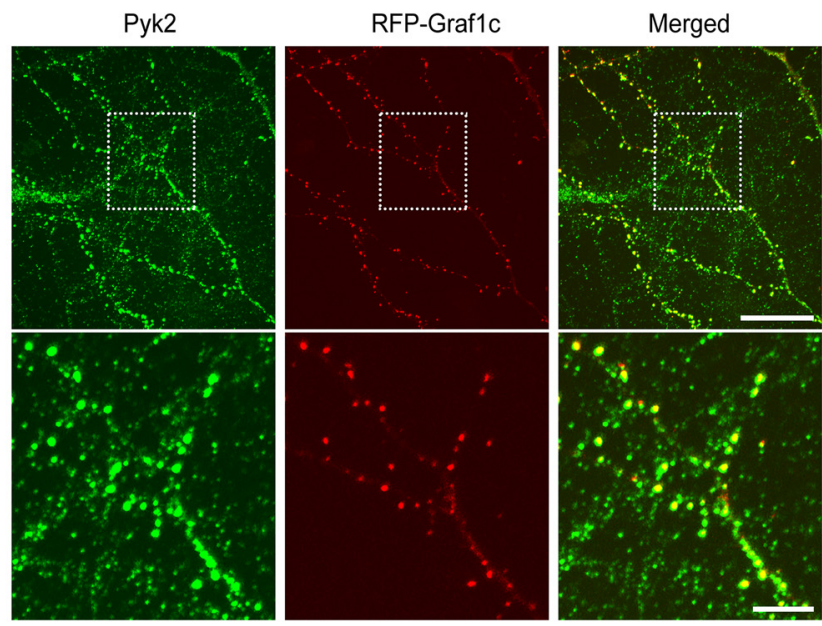

Figure 3. Graf1c colocalizes with Pyk2 to postsynaptic terminal. A, Cultured hippocampal neurons were transfected with GFP and RFP-Graf1c, GFP-Pyk2 and RFP, GFP-Pyk2 and RFP-Graf1c, or GFP-PXXP2 $2_{\text {mut }}$ and RFP-Graf1c at 14 DIV and imaged at 19 DIV without fixation. Bottom, High-magnification images are enlarged views of the rectangle regions on the top. Scale bars: lowmagnification, $25 \mu \mathrm{m}$; high-magnification, $10 \mu \mathrm{m}$. B. Cultured hippocampal neurons expressing GFP-PSD95 and RFP-Graf1c were imaged at 19 DIV. Scale bars: low-magnification, $25 \mu \mathrm{m}$; high-magnification, $10 \mu \mathrm{m}$. C, Quantitation of colocalization in $\boldsymbol{A}$. $\boldsymbol{B}$, Green and Red merged area was divided by total green area. Data are graphed as mean \pm SD ( $n=11,12,10,10 \mathrm{images)}$. ${ }^{* * *} p<0.0001$ by one-way ANOVA, Tukey's multiple-comparisons test. $\boldsymbol{D}$, Immunofluorescence images of endogenous Pyk2 in RFP-Graf1c expressed neuron. Scale bars: Iow-magnification, $20 \mu \mathrm{m}$; high-magnification, $5 \mu \mathrm{m}$.

(Figure legend continued.) D, Graf1c and indicated GFP or GFP tagged Pyk2 and mutants (PXXP1 mut $^{\prime}$ P714AP717A; PXXP2 ${ }_{\text {mut }}$ P857AP860A; $\triangle$ PRD, aa 679-870 deleted; PRD, aa 679870) were cotransfected in Hek293T cells and then immunoprecipitated with anti-GFP antibody and immunoblotted with anti-GFP and anti-Graf1 antibodies. $\boldsymbol{E}$, In vitro direct binding test between purified GST, GST tagged Graf1c, or GST tagged Graf1C SH3 domain (aa 558 - 686) from BL21-DE3 E. coli and $1 \mu \mathrm{g}$ of GFP-Pyk2 from Hek293T cells. Pull-downed protein complexes were separated by SDS-PAGE and stained with Coomassie blue and separately immunoblotted with anti-GFP antibody. F, Hek293T cells were cotransfected with Graf1c and indicated GFP and GFP-Pyk2 constructs. Cells were harvested and immunoprecipitated with an anti-GFP antibody. Immunoblots were probed with anti-Graf1c and anti-GFP antibodies.

mice is equal to that in WT samples at 6 months but is significantly increased by $\sim 50 \%$ during disease progression at 9 and 13 months (Fig. $5 F, G, I$ ). In contrast, Fyn enrichment in the PSD is not altered in the APP/PS1 mice, and Graflc enrichment shows changes of $15 \%$ or less at all ages. Although Pyk2 is increased in the PSD at 9 months, there is no change of Pyk 2 in total S1 fraction (data not shown). Thus, Pyk 2 is enriched at synapses in an $\mathrm{A} \beta \mathrm{o} / \mathrm{APP}$ transgene-dependent manner that correlates with phenotypic progression.

\section{Pyk2 inhibits Graf1c to yield increased RhoA activation}

We considered how Pyk2 redistribution and interaction with Graflc might contribute to synaptic loss of relevance to AD. Although Graf1c provides a postsynaptic binding site for Pyk2 en- 
A

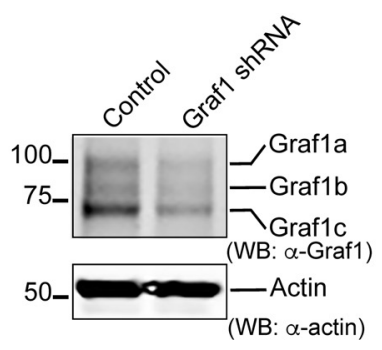

B

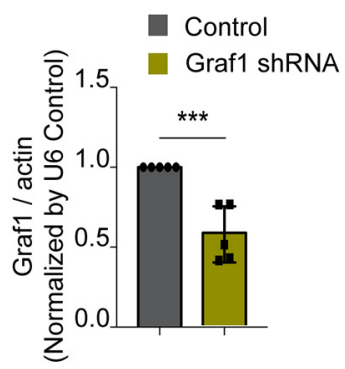

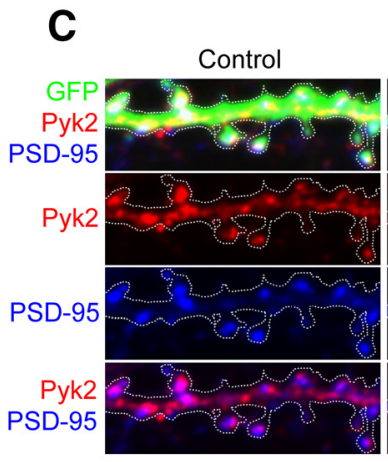

$\mathbf{E}$

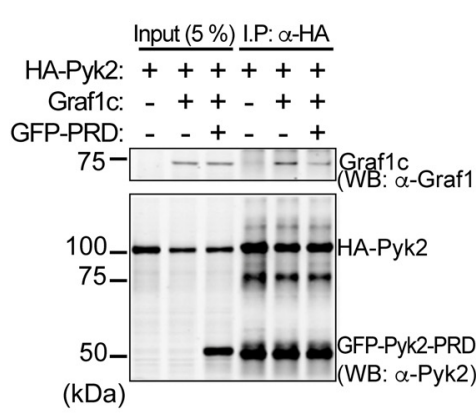

Graf1 shRNA

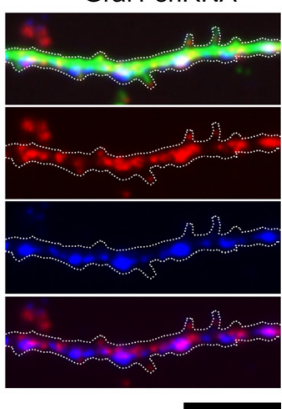

D

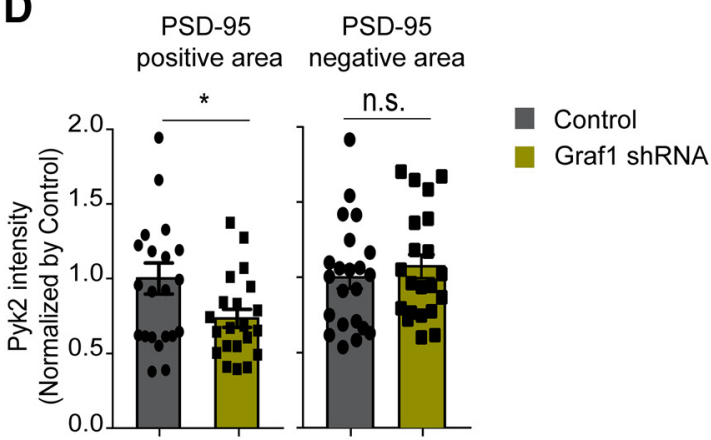

$\mathbf{F}$

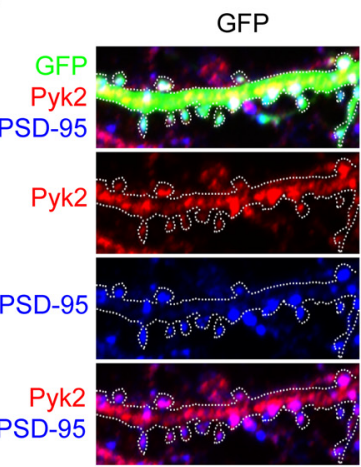

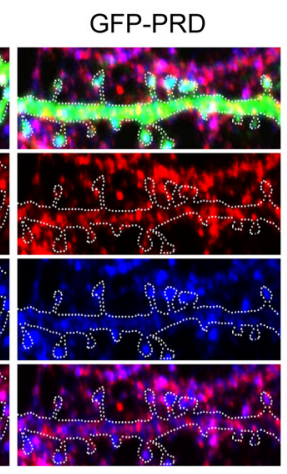

G

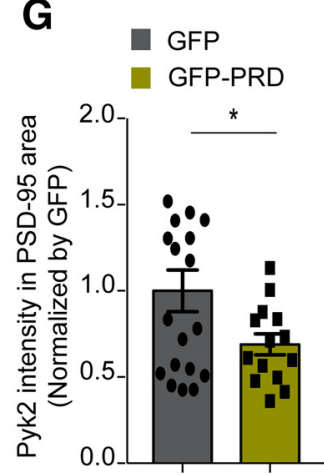

Figure 4. Graf1 regulates Pyk2 localization in postsynaptic terminals in cultured neurons. A, Cultured hippocampal neurons were transfected with either U6 vector (U6 Control) or Graf1-specific shRNA by electroporation before plating. Lysates from 21 DIV transfected neurons were immunoblotted with anti-Graf1 and anti-Actin antibodies. $\boldsymbol{B}$, Densitometric analysis of Graf1 immunoreactivity from $\boldsymbol{A}$ was quantified and normalized to $\mathrm{U} 6$ control. Data are graphed as mean \pm SEM $\left(n=5\right.$ wells). ${ }^{* * *} p<0.001$ by Student's two-tailed $t$ test. $C$, Immunofluorescence of Pyk2 (red) and PSD-95 (blue) in 21 DIV U6 Control vector or Graf1 shRNA transfected neurons. Transfected neurites were marked with white dashed line based on GFP fluorescence. Scale bar, $10 \mu \mathrm{m}$. $\mathbf{D}$, Quantification of Pyk2 levels in synaptic (PSD-95 plus GFP-positive) and extra-synaptic (PSD-95-negative and GFP-positive) areas. Mean \pm SEM (U6 Control, $n=22 ;$ Graf1 shRNA, $n=21 ; n=$ separate neuron). ${ }^{*} p<0.05$ by Student's two-tailed $t$ test. E, Pyk2-PRD competes with Pyk2 and inhibits Graf1c interaction in overexpressed Hek293T cells. Lysates from indicated plasmids transfected Hek293T cells were immunoprecipitated with anti-HA antibodies. The input lysates (5\%) and precipitates were subjected to Western blotting with anti-Graf1 and Pyk2 PRD regionspecific anti-Pyk2 antibodies. F, GFP- or GFP-Pyk2-PRD- (GFP-PRD) expressed neurons were costained with Pyk2 N-terminal-specific (aa 1 100) anti-Pyk2 antibody (red) and PSD-95 antibody (blue). Transfected neurites were marked with white dashed line based on GFP fluorescence. Scale bar, $10 \mu \mathrm{m}$. G, Quantification of postsynaptic terminal localized Pyk2 levels with same method as in C. Mean \pm SEM (GFP, $n=19 ;$ GFP-PRD, $n=14$ neurons). ${ }^{*} p<0.05$ by Student's two-tailed $t$ test.

richment, we hypothesized that Pyk2 in turn regulates the RhoGAP activity of Graflc to alter spine morphology. RhoA signaling is a well known modulator of F-actin and dendritic spine dynamics (Tashiro et al., 2000; Petratos et al., 2008; Huesa et al., 2010; Bolognin et al., 2014; Newell-Litwa et al., 2015) and has been implicated in $\mathrm{AD}$ (Petratos et al., 2008; Herskowitz et al., 2013; Yang et al., 2013; Chang et al., 2015; Henderson et al., 2016). Thus, $A \beta$ o signaling might enhance Pyk2-Graflc interaction at the synapse, and this interaction might then impair the physiological Graflc-RhoA regulation leading to a net local decrease in Graflc-mediated inhibition of RhoA in the spine head, and driving net dendritic spine retraction.

Given the kinase function of Pyk2, we first tested whether Pyk2 might phosphorylate Graflc. We used an in vitro kinase assay with purified recombinant proteins (Fig. 6A). An antibody against all pY epitopes present detected phosphorylation of Graflc in the presence of Pyk2 and ATP, and no phosphorylation in the absence of ATP. There was a basal level of Pyk2 phosphorylation in the absence of ATP which we attribute to basal autophosphorylation during overexpression in HEK cells. Additionally, kinase-dead Pyk2 (K457A) and the PRD mutant of Pyk2 $\left(\mathrm{PXXP} 2_{\text {mut }}\right)$ were unable to phosphorylate Graflc, suggesting that both domains are necessary for the phosphorylation by Pyk2. To further test the ability of Pyk2 to modulate Graf1c function, we used an in vitro RhoGAP assay with Pyk2, Graflc, and RhoA, and assessed GTP hydrolysis as a measure of Graflc GAP activity. We observed a significant increase in GTP hydrolysis with RhoA and Graflc alone, and a significant decrease with RhoA, Graflc, 
A

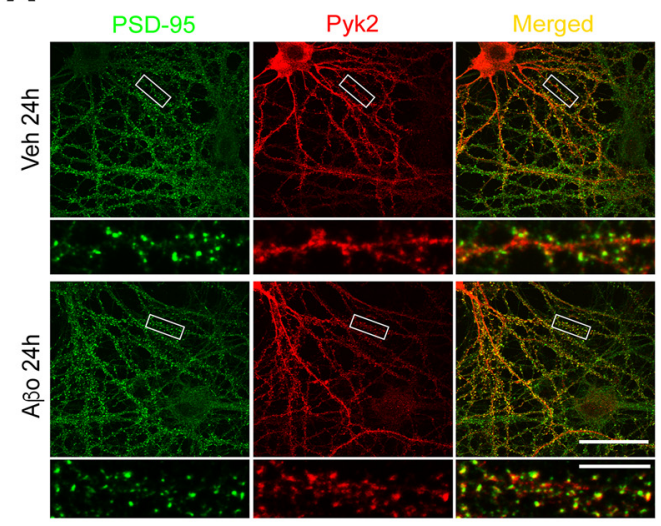

B

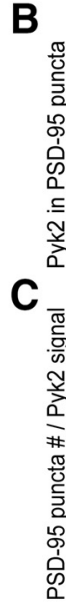

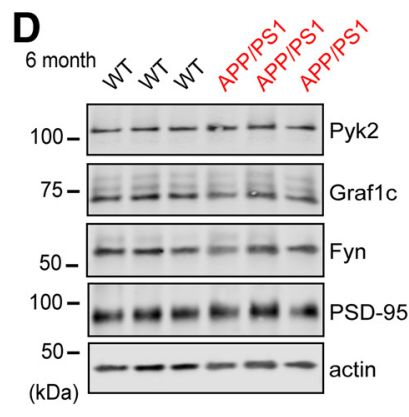

$\mathbf{F}$

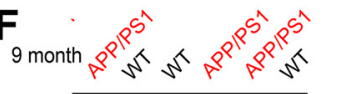

$100-\square \ldots-\ldots$ Pyk2

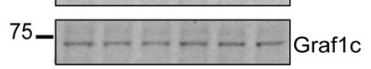

$50--\ldots$ Fyn

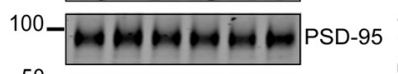
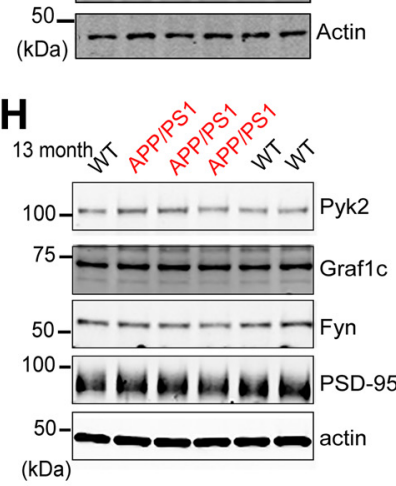
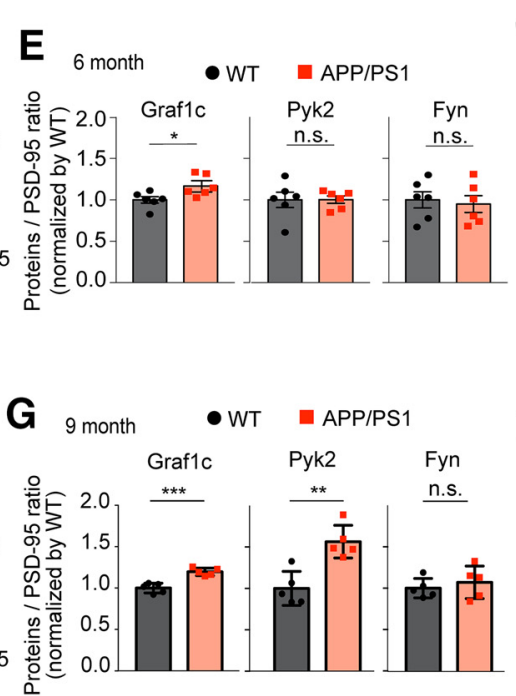

\section{I}
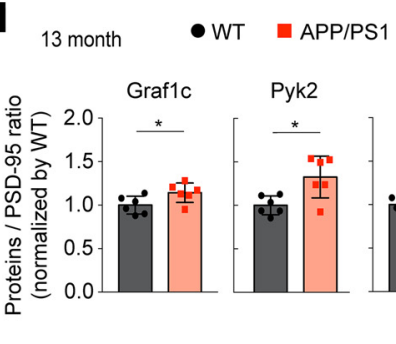

$1 \mathrm{hr}$

$6 \mathrm{hr}$

$24 \mathrm{hr}$

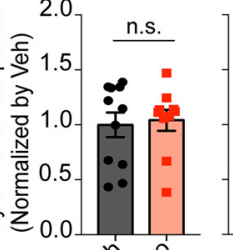

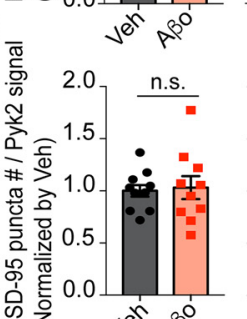
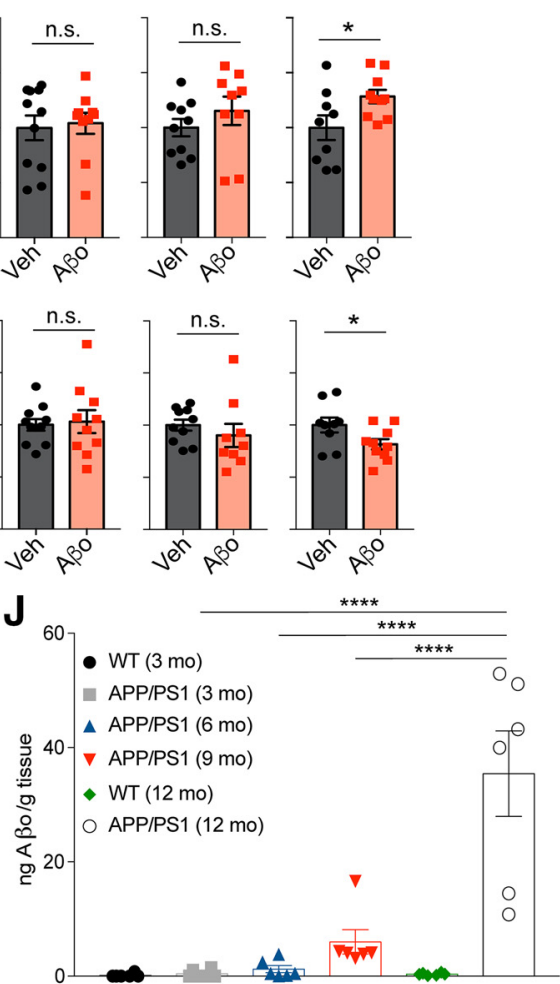

K
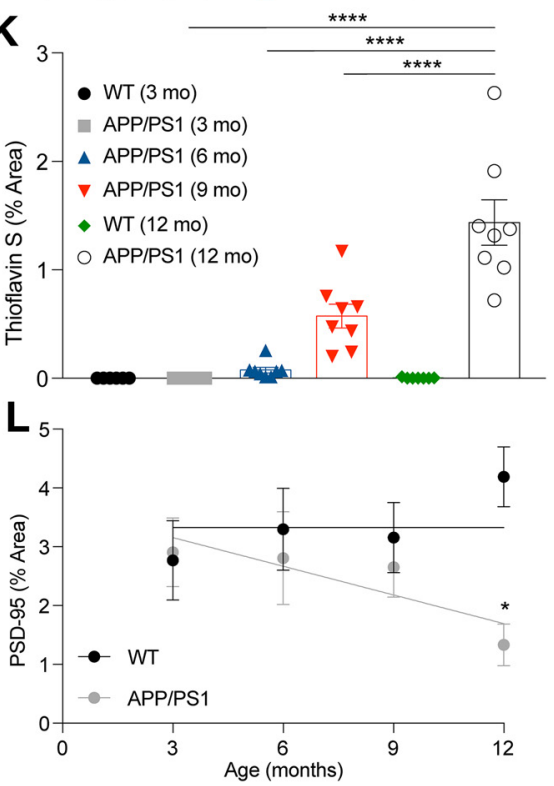

Figure 5. Postsynaptic Pyk2 localization is increased in A $\beta 0$-treated cultured neurons and APP/PS1 mice. $A$, Hippocampal neurons were incubated for $24 \mathrm{~h}$ with Veh or A $\beta 0$ (1 $\mu \mathrm{M}$ monomer, $10 \mathrm{~nm}$ oligomer estimate) in culture media then fixed and stained with anti-Pyk2 and anti-PSD-95 antibodies. Bottom, Enlarged images. Scale bars: top, $40 \mu \mathrm{m}$; bottom, 10 $\mu \mathrm{m} . \boldsymbol{B}, \boldsymbol{C}$, Quantification of Pyk2 immunofluorescence intensity within PSD-95-positive postsynaptic area (B) and PSD-95 puncta number within neuronal area defined by Pyk2 (C). Data are graphed as mean \pm SEM (Veh $1 \mathrm{~h}: n=11 ; \mathrm{A} \beta 01 \mathrm{~h}: n=10$; Veh $6 \mathrm{~h}: n=10 ; \mathrm{A} \beta 06 \mathrm{~h}: n=9$; Veh $24 \mathrm{~h}: n=10 ; \mathrm{A} \beta 024 \mathrm{~h}: n=9$ coverslips from 3 different cultures). ${ }^{*} p<0.05$ by Student's two-tailed $t$ test. D, PSD fractions (20 $\mu$ g proteins) from 6 month WT or APP/PS1 forebrain were subjected to Western blotting with anti-Pyk2, anti-Graf1, anti-Fyn, anti-PSD95, and actin antibodies. $\boldsymbol{E}$, Quantification of Graf1c, Pyk2, and Fyn levels in $\boldsymbol{D}$ normalized to PSD-95. Mean \pm SEM ( $n=6$ mice). $\boldsymbol{F}, \boldsymbol{G}$, Same as $\boldsymbol{D}$ and $\boldsymbol{E}$ but for samples from 9-month-old mice. ${ }^{* *} p<0.01,{ }^{* * *} p<0.001$ by Student's two-tailed $t$ test. $\boldsymbol{H}, \boldsymbol{I}$, Same as $\boldsymbol{D}$ and $\boldsymbol{E}$ but for samples from 13 -month-old mice. ${ }^{*} p<0.05$ by Student's two-tailed $t$ test. $\boldsymbol{J}, \boldsymbol{K}$, Quantification of PrP ${ }^{C}$-interacting A $\beta 0$ from TBS-soluble cortical lysates or Thioflavin-positive plaque burden in sections from mice of the indicated ages. Mean \pm SEM $(n=7$ mice for WT, $n=8$ for all other groups). ${ }^{* * *} p<0.0001$ by one-way ANOVA with Tukey's multiple comparison test. $L$, Quantification of synaptic density from sections of dentate gyrus measured as anti-PSD-95-immunoreactive area. Mean \pm SEM ( $n=8$ mice for all groups). ${ }^{*} p<0.05$ by one-way ANOVA with Tukey's multiple-comparison test.

and GFP-Pyk2 (Fig. 6B). Consistent with our hypothesis, Pyk2 mutants K457A and PXXP2 ${ }_{\text {mut }}$ were not able to significantly reduce GTP hydrolysis compared with RhoA and Graflc alone. These data suggest that both kinase and PRD regions of Pyk2 are necessary to modulate Graf1c GAP activity. These in vitro assays tested the ability of Pyk2-Graf1c-RhoA to interact directly, but we also sought to test the ability of Pyk2 to modulate Graf1c in cells. We used a GST-RBD (Rhotektin RhoA-binding domain) 

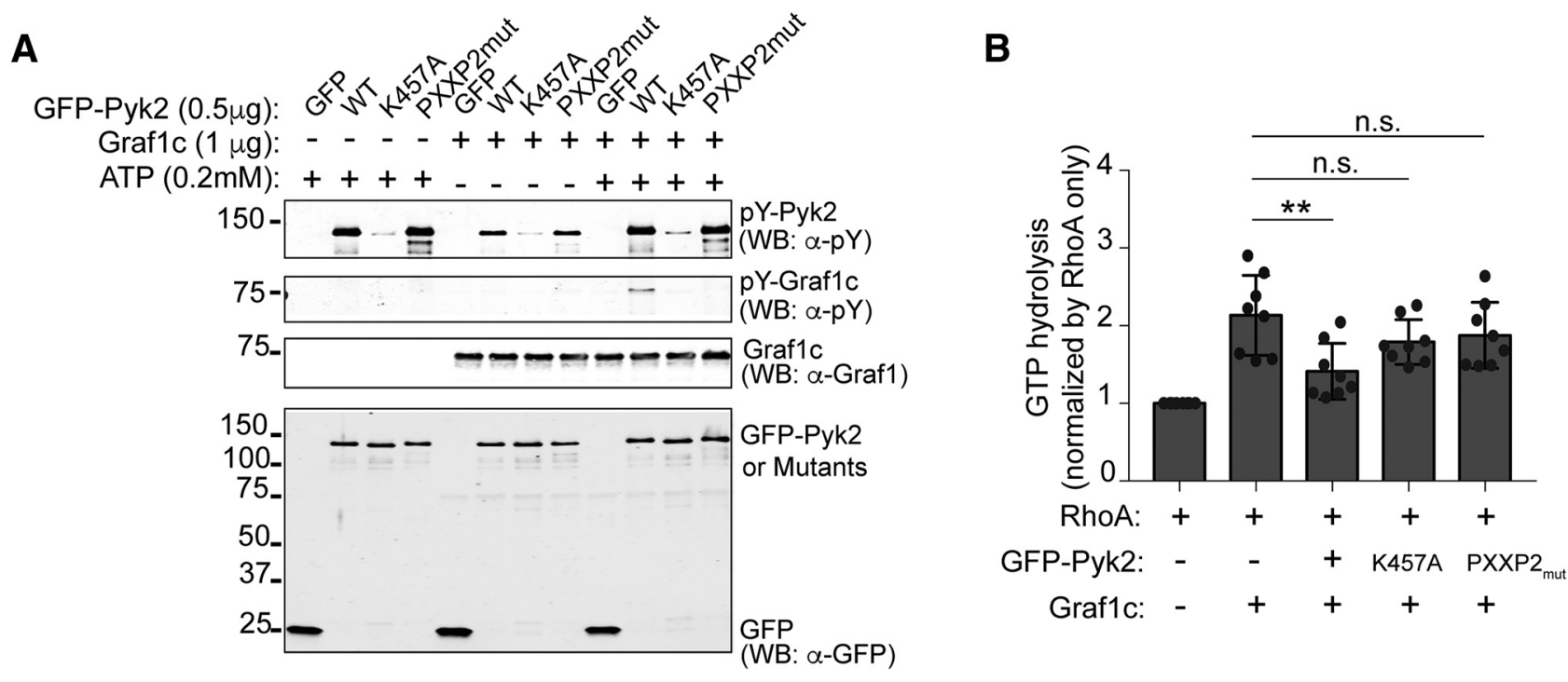

C

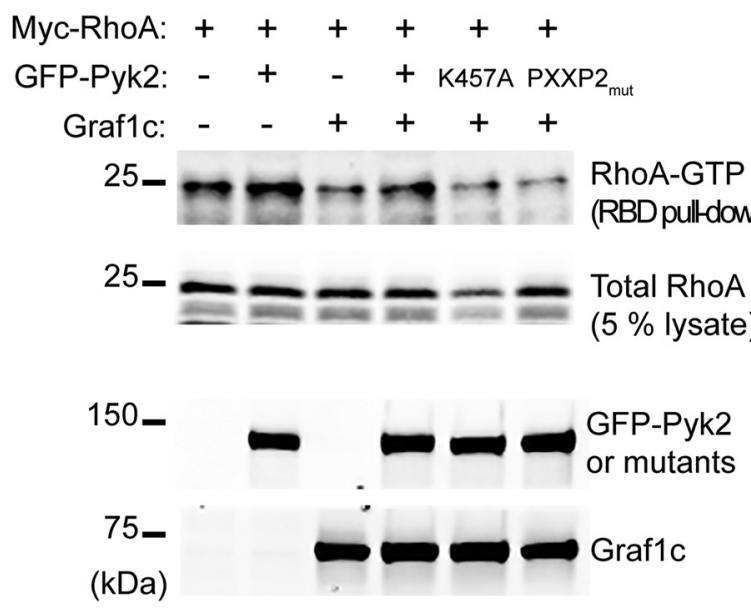

D

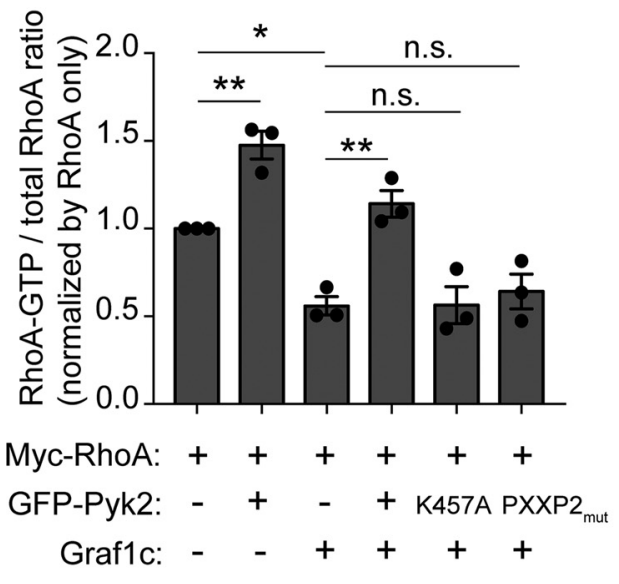

Figure 6. Pyk2 induces RhoA activation through Graf1c interaction and phosphorylation. $\boldsymbol{A}$, In vitro Pyk2 kinase assay with recombinant Graf1c as a substrate. Purified Graf1c from bacteria and GFP or GFP tagged Pyk2, K457A, and PXXP2mut from Hek293T cells were incubated in the absence or presence of ATP for 30 min at room temperature. Proteins were separated by SDS-PAGE and immunoblotted with indicated antibodies. $\boldsymbol{B}$, In vitro RhoGAP assay with recombinant RhoA protein. The phosphate generated by the hydrolysis of GTP by RhoA GTPase is measured to determine the Graf1c GAP activity. The $y$-axis represents the relative ratio in indicated reactions compared with in RhoA only. Data are graphed as mean $\pm S E M\left(n=8\right.$ experiments). ${ }^{* *} p<0.01$ by one-way ANOVA, Tukey's multiple-comparisons test. C, GST-RBD pull-down assay from Hek293T cell lysate from cells transfected with the indicated expression plasmids. The proteins retained by GST-RBDimmobilized beads and lysates were subjected to immunoblotting with anti-Myc, anti-Pyk2, anti-Graf1 antibodies. D, Levels of RhoA-GTP (RBD pull-down) and RhoA-total (5\% lysate) were quantified by densitometric measurement. The $y$-axis represents the relative ratio in indicated cells compared with in Myc-RhoA only expressing cells. Data are graphed as mean \pm SEM $(n=3$ experiments). ${ }^{*} p<0.05,{ }^{* *} p<0.01$ by one-way ANOVA, Tukey's multiple-comparisons test.

pull-down assay to measure activated RhoA-GTP in Hek293T cells overexpressing Myc-RhoA, Graf1c, GFP-Pyk2, catalytically inactive Pyk2 (K457A), and Pyk2 PRD mutant (PXXP2 $2_{\text {mut }}$; Fig. $6 C, D)$. The observed ability of Graf1c overexpression alone to reduce RhoA-GTP activity below baseline is consistent with its known GAP activity for RhoA. Coexpression of GFP-Pyk2 together with Graflc lead to an increase in active RhoA-GTP compared with Graf1c alone, consistent with Pyk2 inhibiting Graf1c-GAP function. The Pyk2-dependent increase of RhoAGTP with Graflc present does not occur with the Pyk2 mutants, K457A or PXXP2 2 mut Overexpression of GFP-Pyk2 alone significantly increased RhoA-GTP levels, and this is consistent with inhibition of the low level of endogenous Graflc present in Hek293T cells (Fig. 6D). Overall, inhibition of Graf1c to increase RhoA-GTP requires both the kinase and PRD regions of Pyk2.

\section{$\mathrm{A} \beta \mathrm{o}$ and $\mathrm{AD}$ transgene effects on RhoA activity are mediated} by Pyk2

Based on these protein interactions, we hypothesized that $A \beta O$ drives Pyk2 recruitment to postsynaptic sites to impair local Graflc regulation of RhoA and F-actin. We examined this possibility by performing the RBD pull down assay on acute brain slices treated with $\mathrm{A} \beta \mathrm{o}$ or vehicle from $\mathrm{WT}$ and $\mathrm{Pyk} 2^{-1-}$ mice (Fig. $7 A, B$ ). There was a significant $\mathrm{A} \beta \mathrm{O}$-induced increase in activated RhoA in WT mice, and this increase was not observed in Pyk $2^{-1-}$ slices. To assess the in vivo AD relevance of this pathway, we examined the RBD pull-down from aged WT and APP/PS1 forebrain lysates. In the APP/PS1 strain, A $\beta$ o levels rise, synapses are lost, and memory is impaired progressively from 6 through 13 months of age (Fig. 5J-L; Jankowsky et al., 2004; Janus et al., 2015; Hong et al., 2016). Paralleling the temporal pattern of these phe- 
A

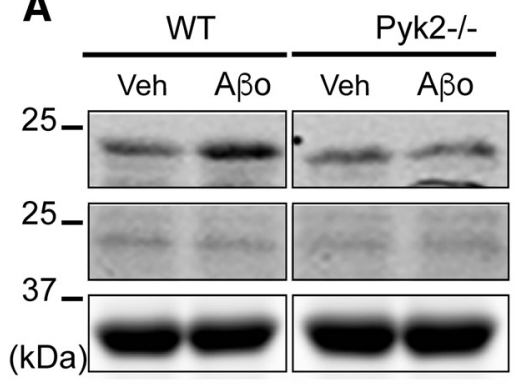

C
RhoA-GTP (RBD pull-down)

Total RhoA (5\% lysate)

GST-RBD (Coomassie blue)
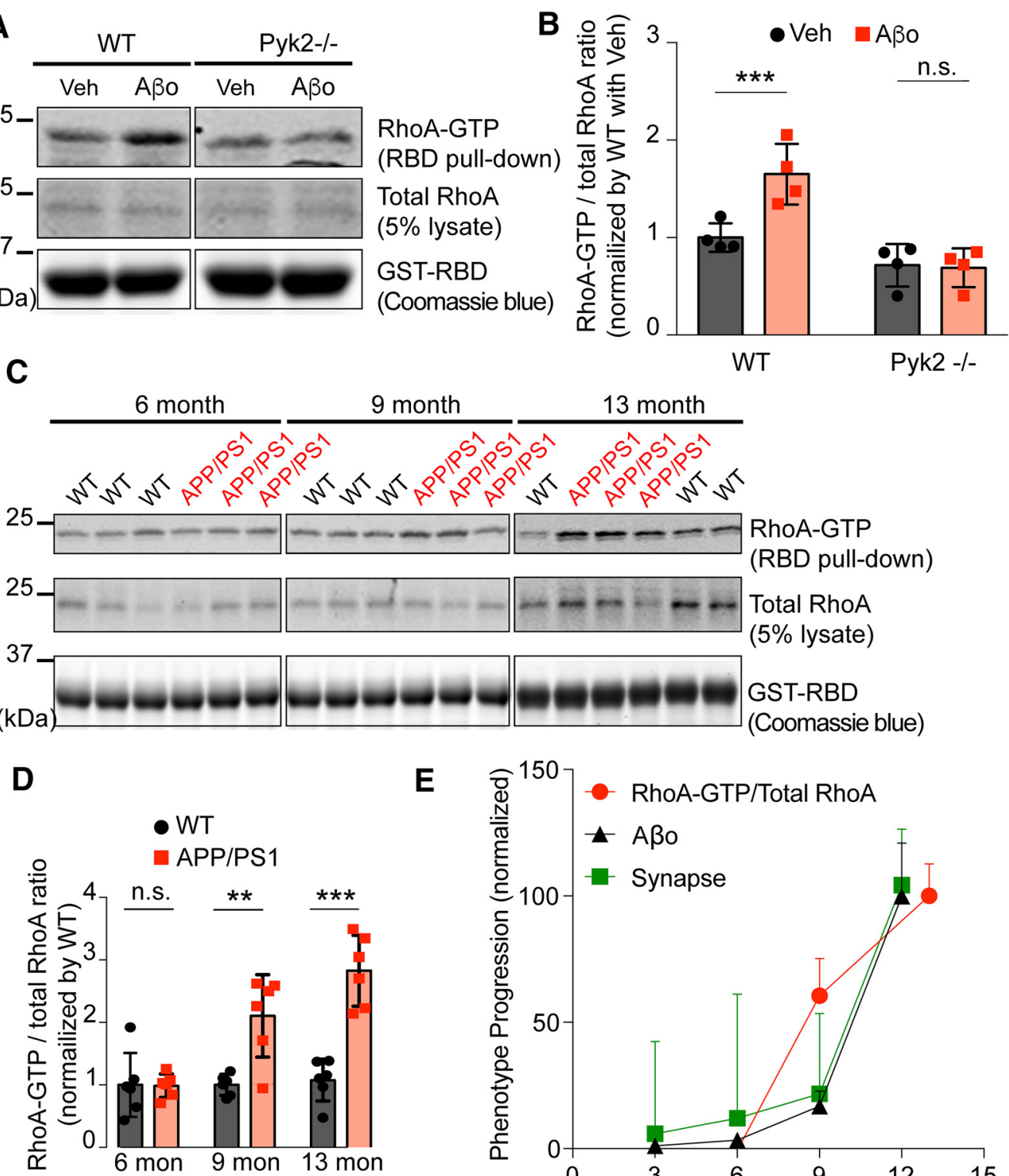

E

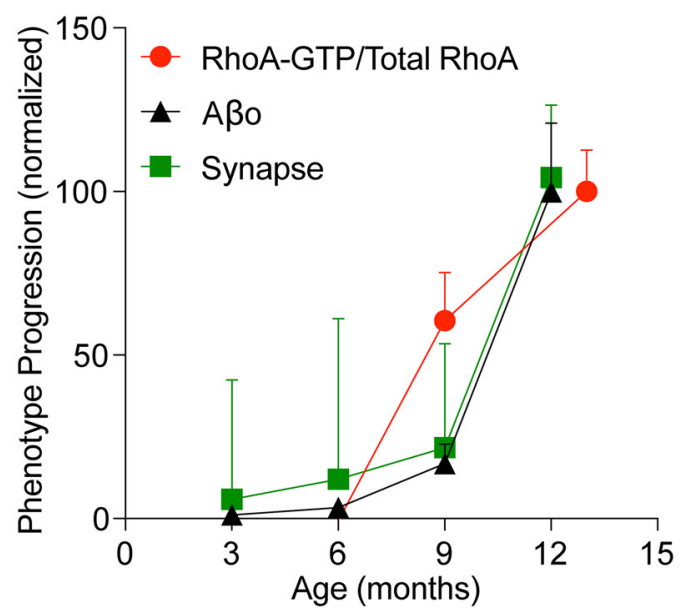

Figure 7. Pyk 2 is required for RhoA activation by $A \beta 0$ in neurons and RhoA is activated in AD transgenic mice. $A$, GST-RBD pull-down assay in the Veh or A $\beta 0$-treated acute brain slice from WT or Pyk $2^{-1-}$ mice. The pull-down proteins and lysates were subjected to immunoblotting with anti-RhoA antibody. The bait proteins amount was examined by Coomassie blue staining from $50 \%$ of pull-down samples. $B$, Quantification of RhoA-GTP/total RhoA ratio by densitometric analysis. The ratio was normalized to Veh-treated WT. Data are graphed as mean \pm SEM ( $n=4$ separate experiments). ${ }^{* * *} p<0.001$ by Student's two-tailed $t$ test. C, GST-RBD pull-down assay of forebrain lysates from 6-, 9-, or 13-month-old WT and APP/PS1 mice. The pull-down proteins and lysates were subjected to immunoblotting with anti-RhoA antibody. The bait proteins amount was examined by Coomassie blue staining from $5 \%$ of pull-down samples. D, Quantification of RhoA-GTP/total RhoA ratio by densitometric analysis. The ratio was normalized to age-matched WT. Data are graphed as mean \pm SEM ( $n=6$ mice for each condition). ${ }^{* *} p<0.01$, ${ }^{* * *} p<0.001$ by Student's two-tailed $t$ test. $E$, Data were normalized with the lowest value $=0$ and the highest value $=$ to 100 . Data are graphed as mean $\pm S E M$. The $A \beta 0$ level and synapse density loss data were derived from Figure $5 J$ and $L$, respectively.

notypes, there is a significant increase of RhoA-GTP levels in APP/PS1 mice at 9 and 13 months of age compared with WT mice or APP/PS1 mice at 6 months of age (Fig. $7 C-E$ ). These data show that RhoA activity increases with phenotype progression including synapse loss and $\mathrm{A} \beta \mathrm{O}$-dependent synaptic dysfunction, in a Pyk2-dependent manner.

\section{Pyk2-Graf1c interaction drives dendritic spine loss through} RhoA activation

Next, we evaluated whether RhoA activity is necessary for Pyk2dependent decrease in dendritic spine density. As described above, overexpression of GFP-Pyk2 induces loss of half of hip- pocampal neuron dendritic spines. Consistent with the Pyk2Graflc-RhoA interaction mediating this spine density reduction, the Pyk2 PRD mutant PXXP2 $2_{\text {mut }}$, which fails to interact with Graflc or regulate RhoA, does not display reduced spine density compared with GFP control (Fig. 8A,B). Treating neurons with the Rho/Rock pathway inhibitor Y-27632 (Bito et al., 2000), or coexpression of dominant-negative RhoA-T19N (Gebbink et al., 1997), each fully rescue GFP-Pyk2-induced spine loss. Overexpression of Graf1c counteracts the ability of Pyk2 to suppress dendritic spine density. Furthermore, knockdown of Graflc expression induces a significant decrease of spine density, and both Y-27632 treatment and RhoA-T19N coexpression rescue Graf1c- 
A

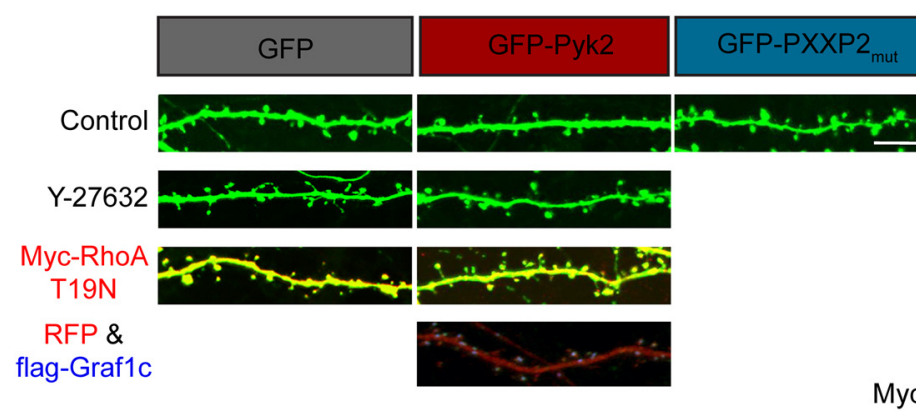

C

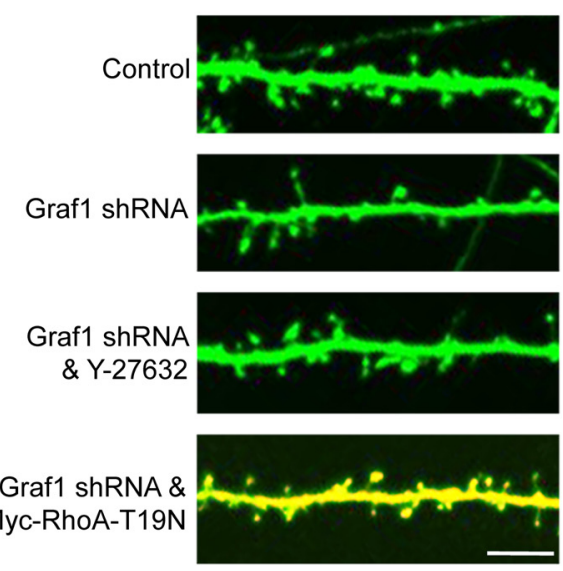

B

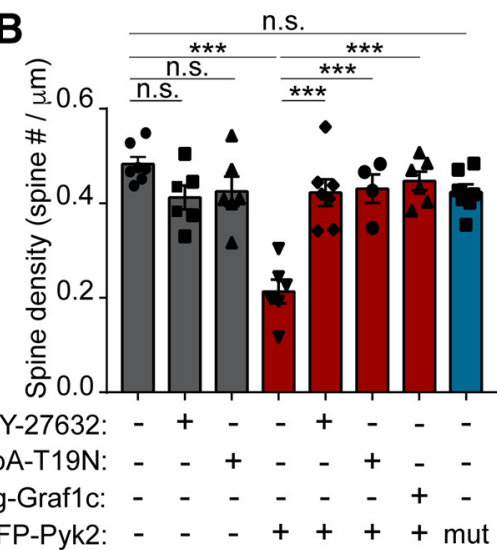

D

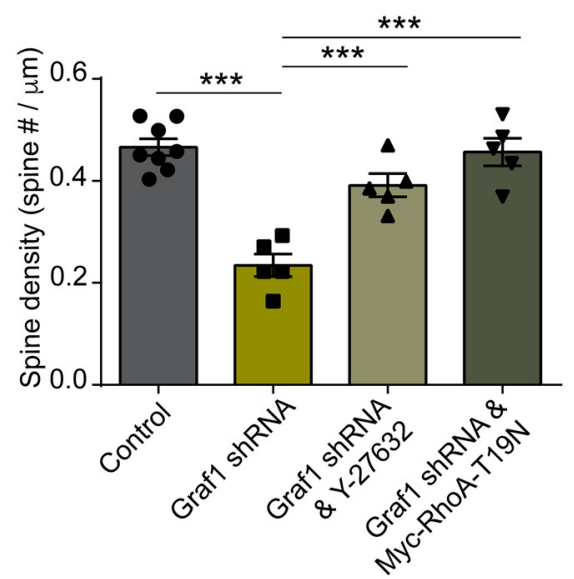

Figure 8. Pyk2 and Graf1c regulate RhoA activity and dendritic spine loss. $A$, Representative GFP fluorescence images of the cultured hippocampal neurons. Neurons were transfected with GFP, GFP and Myc-RhoA-T19N, GFP-Pyk2, GFP-Pyk2 and Myc-RhoA-T19N, GFP-Pyk2 and flag-Graf1C, or GFP-PXXP2 $2_{\text {mut }}$ then incubated in the presence or absence of $10 \mu \mathrm{M}$ Y-27632 at 17 DIV and then fixed at 21 DIV. The Myc-RhoA-T19N and flag-Graf1c expressions were examined by immunostaining with anti-Myc and anti-flag antibodies. Scale bar, $10 \mu \mathrm{m}$. B, Quantification of dendritic spine density. Data are graphed as mean \pm SEM (GFP: $n=7$; GFP and Y-27632: $n=6$; GFP and Myc-RhoA-T19N: $n=6$; GFP-Pyk2: $n=9$; GFP-Pyk2 and Y-27632: $n=7$; GFP-Pyk2 and Myc-RhoA-T19N: $n=5$; GFP-Pyk2 and flag-Graf1c: $n=6$; GFP-PXXP2 $2_{\text {mut }}: n=7$ coverslips from 3 different cultures). ${ }^{* * *} p<0.001$ by ANOVA, Tukey's multiple-comparisons test. C, Representative fluorescence images of cultured hippocampal neurons. Neurons were transfected with U6 vector (Control), Graf1 shRNA, Graf1 shRNA, and $10 \mu \mathrm{M}$ Y-27632, or Graf1 shRNA and Myc-RhoA-T19N at 14 DIV and then fixed at 21 DIV. Scale bar, $10 \mu \mathrm{m}$. D, Quantification of dendritic spine density in the transfected neurons. Data are graphed as mean \pm SEM (Control: $n=8$; Graf1 shRNA: $n=5 ;$ Graf1 shRNA and Y-27632: $n=5$; Graf1 shRNA and Myc-RhoA-T19N: $n=5$ coverslips from 3 different cultures). ${ }^{* *} p<0.001$ by one-way ANOVA, Tukey's multiple-comparisons test.

knockdown-induced spine loss (Fig. 8C,D). Therefore, we conclude that, in response to $\mathrm{A} \beta \mathrm{o}$, Pyk2 interacts with Graf1c within dendritic spines to allow increased RhoA-GTP levels and subsequent reduced synapse density.

\section{Pyk2 signaling mediates A $\beta$ o-dependent dendritic spine deficits in primary neurons}

These effects of a postsynaptic Pyk2 pathway suggests that ADmediated gain of Pyk2 function might underlie synapse loss by altering actin-based spine dynamics (Fischer et al., 1998; Tashiro et al., 2000). We monitored actin-dependent spine motility in primary hippocampal neurons treated with vehicle or $\mathrm{A} \beta \mathrm{o}$ for $24 \mathrm{~h}$ (Fig. $9 A, B$ ). We quantified motility as the time-dependent SD of change in dendritic spine profiles during 5 min with $0.1 \mathrm{~Hz}$ image captures. There is a significant decrease in spine motility from WT neurons treated with $\mathrm{A} \beta \mathrm{o}$ compared with WT vehicle treated neurons. To ensure that the spine motility we measured is actin-dependent, we treated neurons with cytochalasin $\mathrm{D}$, an inhibitor of actin polymerization (Cooper, 1987), and observed near complete cessation of spine motility (Fig. 9C,D). Consistent with a gain-of-function hypothesis for Pyk2, genetically deleting Pyk2, inhibiting Pyk2 with PF-719, blocking the Pyk2-Graf1c interaction with Pyk2-PRD, or inhibiting Rho/Rock signaling with Y-27632 are each able to fully rescue the $\mathrm{A} \beta \mathrm{o}$-induced decrease in spine motility (Fig. $9 A, B$ ). Thus, the Pyk $2 /$ Graflc/RhoA pathway mediates an $\mathrm{A} \beta \mathrm{o}$ driven deficit in spine motility.

We considered whether the acute effects of $\mathrm{A} \beta \mathrm{O}$-induced, Pyk2-mediated decrease on spine motility might be translated into reduced spine number over longer time periods. We measured dendritic spine density in populations of vehicle and $\mathrm{A} \beta$ o-treated primary hippocampal neurons. Previously, we demonstrated that tracking single spines over $6 \mathrm{~h}$ detects a loss of $\sim 6-8 \%$ of spines in the presence of $A \beta o$, but not vehicle (Um et al., 2012, 2013). At $6 \mathrm{~h}$ this loss is not significant by endpoint population analysis of dendritic spine density (Fig. 10A,B). Nonetheless, after $4 \mathrm{~d}$, there is significant net reduction of spine density by $25 \%$ in the $\mathrm{A} \beta$ o-treated WT cultures (Fig. $10 A, B$ ). In contrast, $\mathrm{Pyk} 2^{-1-}$ neurons treated with $\mathrm{A} \beta \mathrm{o}$ display no dendritic spine loss at $6 \mathrm{~h}$ or $4 \mathrm{~d}$ compared with vehicle-treated controls (Fig. 10C,D). Consistent with the Pyk2 gain-of-function hypothesis, small molecule inhibition of Pyk2 with PF-719, blocking the Pyk2-Graf1c interaction with Pyk2-PRD, or inhibiting RhoA activity with dominant-negative RhoA-T19N is each able to fully rescue $\mathrm{A} \beta \mathrm{o}$-dependent spine loss (Fig. $10 E, F$ ). Furthermore, PF719, Pyk2-PRD, or RhoA-T19N alone had no effect on spine 
A

Spine motility (STD projection)
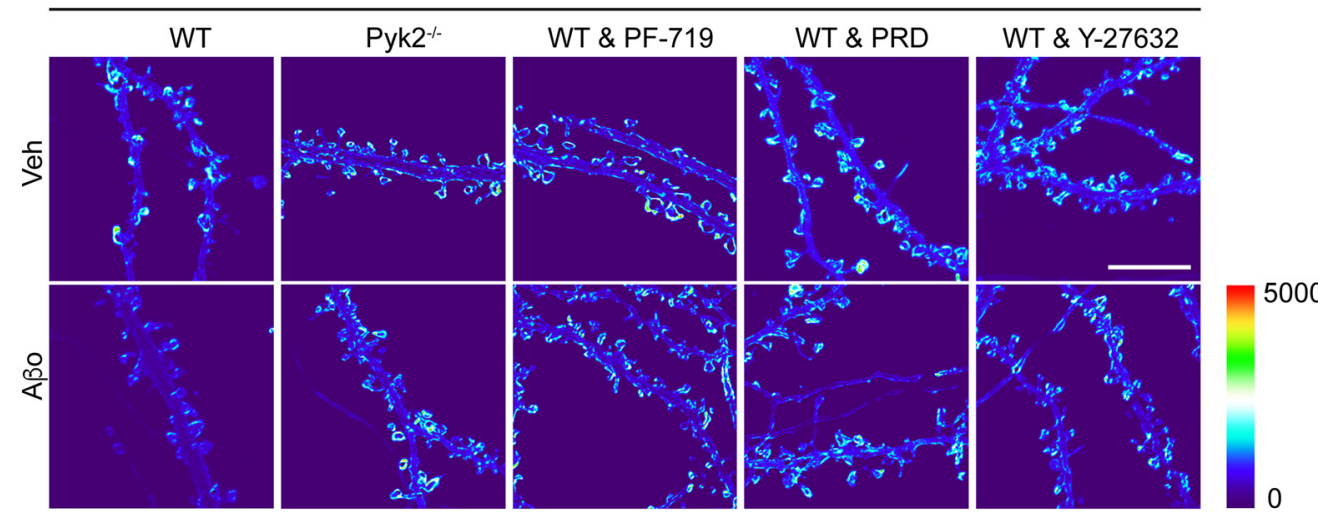

B

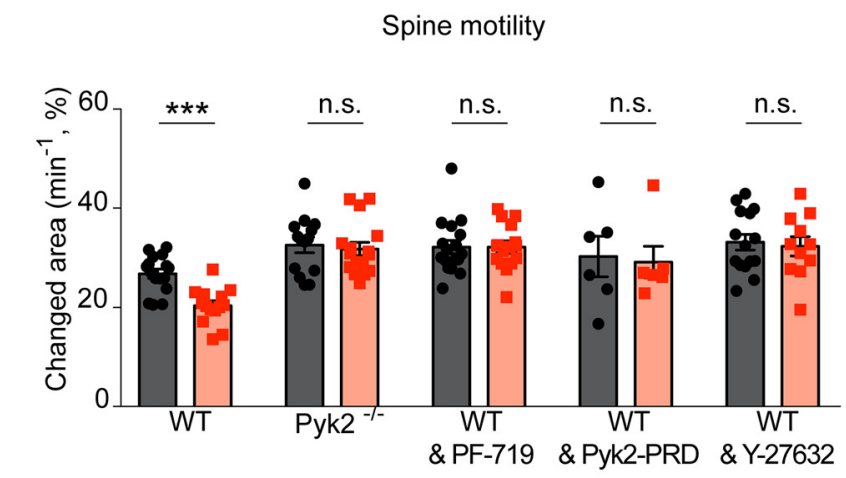

- Veh

- AßO

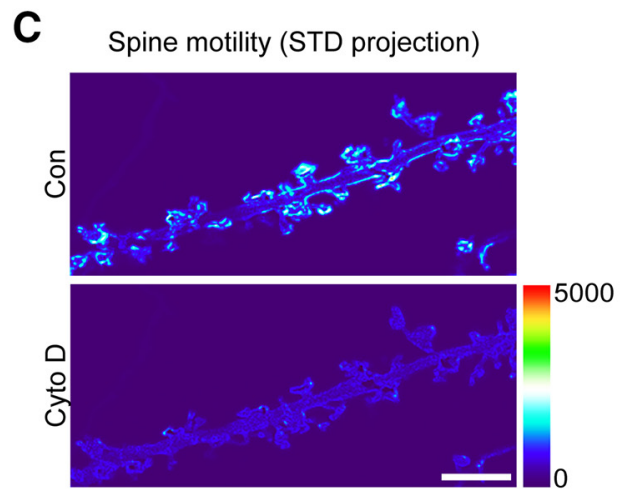

D

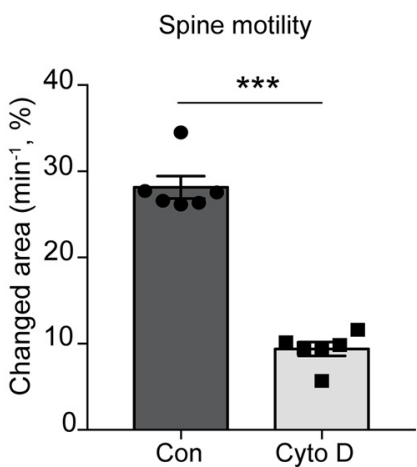

Figure 9. A $A 0$-inhibition of F-actin-dependent dendritic motility is prevented by deletion of Pyk2 and RhoA inhibition in primary neurons. $A$, Representative images of dendritic spine motility by SD projection of time-lapse image. Myristoyl-GFP-expressing hippocampal neurons (21 DIV) from WT or Pyk2 ${ }^{-1-}$ mice were imaged for 5 min with 10 sintervals after Veh or A $\beta 0$ ( $1 \mu \mathrm{m} \mathrm{monomer,} 10 \mathrm{~nm}$ oligomer estimate) pre-incubation with or without $1 \mu \mathrm{m}$ PF-719, RFP-Pyk2-PRD (PRD), or $10 \mu \mathrm{m}$ Y-27632 for $24 \mathrm{~h}$. The SD value for each pixel is shown by thermal color scale. Scale bar, $10 \mu \mathrm{m}$. B, Quantification of spine motility, expressed as percentage of changed area of spines with subtraction of changed area of dendritic shaft as background [changed area $\left.=\left(\Delta A_{\text {spine }} / A_{\text {spine }} \times 100\right)-\left(\Delta A_{\text {shaft }} / A_{\text {shaft }} \times 100\right)\right]$. Data are graphed as mean \pm SEM (Veh in WT: $n=16 ; A \beta 0$ in WT: $n=14 ;$ Veh in Pyk2 ${ }^{-1-}: n=14 ; A \beta 0$ in Pyk2 ${ }^{-1-}: n=16$; Veh in WTand PF-719: $n=17 ; A \beta 0$ in WTand PF-719: $n=16 ;$ Veh in WT and Pyk2-PRD: $n=6 ; A \beta 0$ in WT and Pyk2-PRD: $n=6$; Veh in WT and Y-27632: $n=15 ; A \beta 0$ in WT and Y-27632: $n=11$ neurons from 3 different cultures). ${ }^{* * *} p<0.001$ by Student's two-tailed $t$ test. C, Representative images of dendritic spine motility by SD projection of time stacks. Hippocampal neurons (21 DIV) expressing myristoyl-GFP were imaged for 5 min with 10 s intervals as a control and then incubated with $1 \mu \mathrm{m}$ cytochalasin D for 20 min, imaged again with same acquisition protocol as control image at the sameneuron. To display the spine motility in time-lapse images, the timestackimages over 5 min of each conditions were projected to SD using Image and color-coated with thermal color scale. Scale bar, $10 \mu \mathrm{m}$. D, Quantification of spine motility, expressed as percentage of changed area of spines with subtraction of dendritic shaft area change [changed area $\left.=\left(\Delta \mathrm{A}_{\text {spine }} / \mathrm{A}_{\text {spine }} \times 100\right)-\left(\Delta \mathrm{A}_{\text {shaft }} / \mathrm{A}_{\text {shaft }} \times 100\right)\right]$. Mean $\pm \operatorname{SEM}(n=5$ coverslips $)$.

density. These data suggest that Pyk2 mediates A $\beta$ o-dependent dendritic spine deficits in primary neurons.

\section{Discussion}

The present study demonstrates that activation of the $\mathrm{AD}$ risk gene product Pyk2 functions locally in neurons to mediate synapse loss. The RhoA GAP protein, Graf1c, is a physical interactor and substrate of Pyk2, and RhoA activation with altered actin dynamics mediates Pyk2-induced net retraction of dendritic spines. $\mathrm{A} \beta$ oligomeric species stimulate Pyk2 to translocate to the
PSD, to engage this Graflc/RhoA pathway and to reduce the density of synaptic structures. In $\mathrm{AD}$, the Pyk2 protein is activated by an $\mathrm{A} \beta \mathrm{o} / \mathrm{PrP} \mathrm{C}^{\mathrm{C}} / \mathrm{mGluR} 5 / \mathrm{Fyn}$ complex to reduce dendritic spine density (Fig. 11). Thus, inhibition of Pyk2 kinase provides a potential target for disease-modifying $\mathrm{AD}$ intervention.

Our analysis of brain proteins interacting with Pyk2 identified Graf1c, consistent with a previous report (Ohba et al., 1998). Here, we show that the two proteins colocalize at postsynaptic sites. Furthermore, their interaction is functionally bidirectional 
A
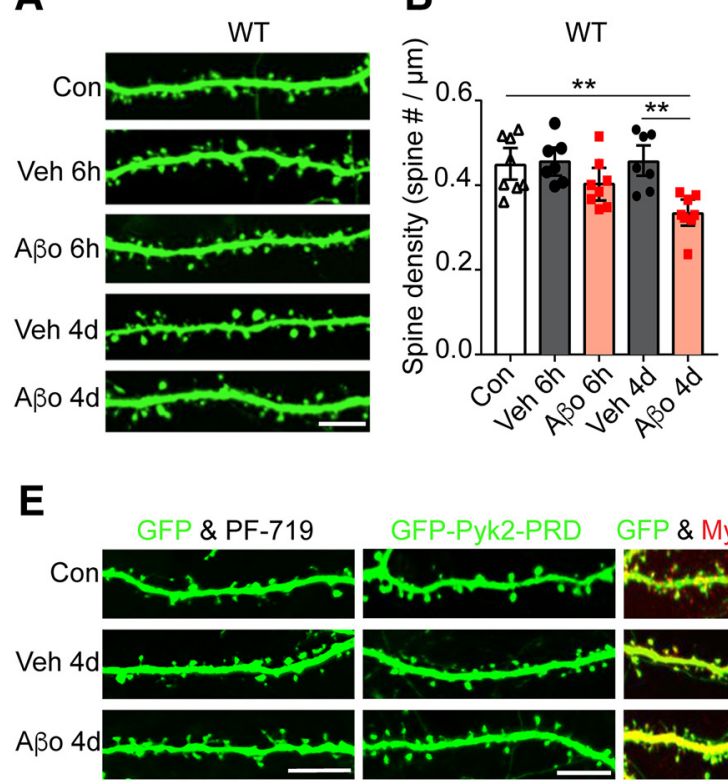

B

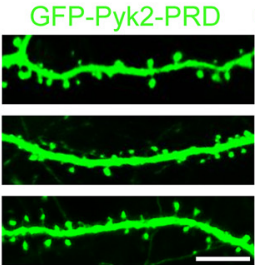

C

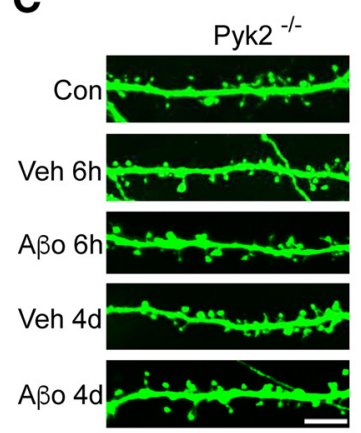

$\mathbf{F}$

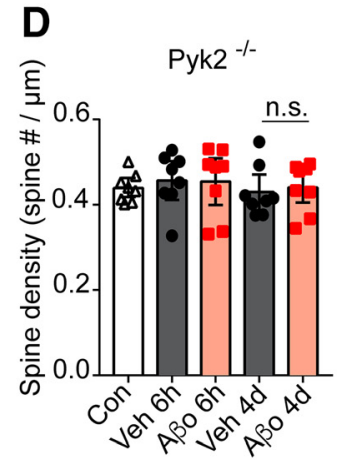

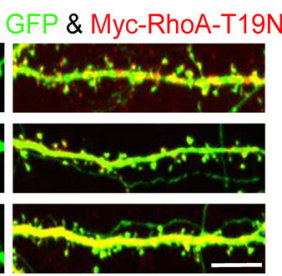

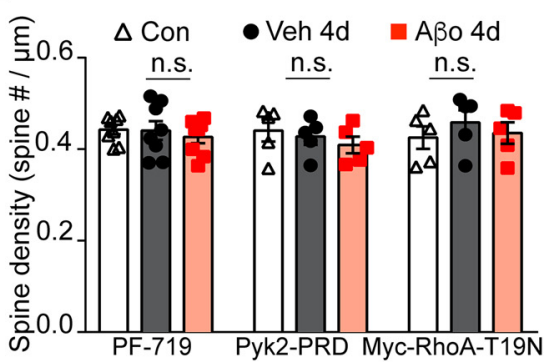

Figure 10. $A \beta 0$-induced dendritic spine loss are prevented by deletion of Pyk2 or RhoA inhibition. $A, C$, Representative images of 21 DIV GFP transfected hippocampal neurons (21 DIV) from WT mice $(\boldsymbol{A})$ or Pyk2 ${ }^{-1-}$ mice $(\boldsymbol{C})$ after non-treated (Con), Veh, or $A \beta 0$ treatment for $6 \mathrm{~h}$ or $4 \mathrm{~d}$. $\boldsymbol{B}, \boldsymbol{D}$, Quantification of dendritic spine density for conditions shown in $\boldsymbol{A}$ and $\boldsymbol{C}$. Data are graphed as mean \pm SEM ( $n=7-8$ coverslips from 3 different cultures). ${ }^{* *} p<0.01$ by ANOVA, Tukey's multiple-comparisons test. E, F, GFP, GFP-Pyk2-PRD, or GFP and Myc-RhoA-T19N transfected neurons were incubated with Veh or $A \beta 0$ for $4 \mathrm{~d}$ and then fixed and stained with anti-Myc antibodies at 21 DIV. Mean \pm SEM $(n=5-8$ coverslips from 3 different cultures). One-way ANOVA, Tukey's multiple-comparisons test.

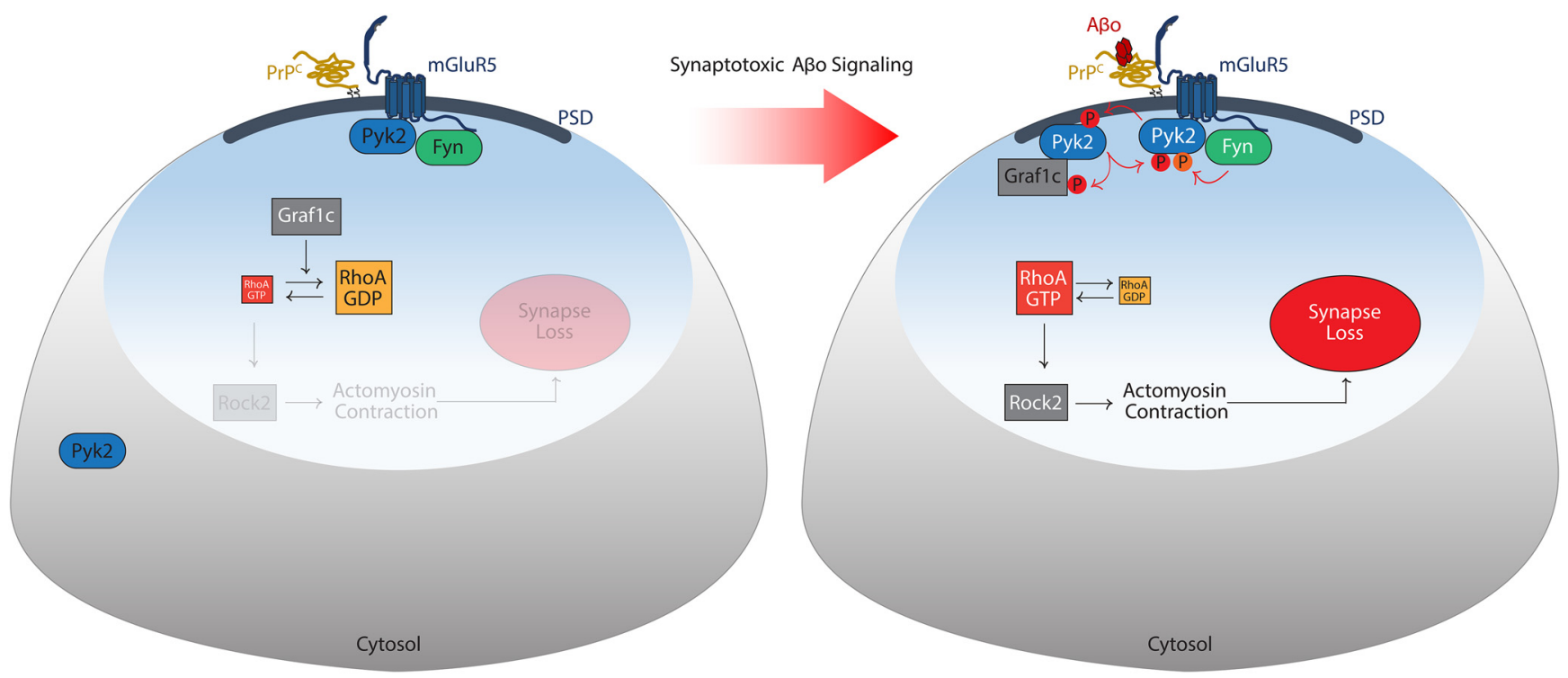

Figure 11. Model for Pyk2 action in AD risk. The proposed mechanism for Pyk2 in A 30 -induced AD signaling at the PSD of dendritic spines is illustrated. In the healthy basal state at left, Pyk2 and Fyn activation is limited (black lettering) and Graf1c actively (white lettering) suppresses RhoA signaling to the actin cytoskeleton to maintain synaptic morphology. In AD (right), $A \beta 0$ binds to PrP $C$ to engage mGluR5 and activate Fyn kinase (white lettering). Fyn phosphorylates Pyk2 kinase (white lettering, orange P) this leads to Pyk2 activation (white lettering), autophosphorylation (red P) and Pyk2 recruitment to the PSD. Pyk2 physically interacts with Graf1c at the PSD, phosphorylates Graf1c (red P) and inactivates Graf1c GAP activity (black lettering). Loss of Graf1c function allows increased active RhoA GTPase and subsequent ROCK2-dependent actin contractility, to retract dendritic spines and cause synapse loss. Human genetic variants at the Pyk2 locus, which have been shown to increase Pyk2 mRNA expression, enhance this pathway and thereby increase AD risk.

in the sense that Graf1c increases synaptic localization of Pyk2, whereas Pyk2 titrates Graf1c activity as a RhoA GAP. Interaction of the two proteins requires the Pyk2 PRD, and Pyk2 is able to directly phosphorylate Graf1c. Additionally, Pyk2 kinase activity is essential for Pyk2 suppression of the GAP activity of Graf1c for RhoA. Graf1c recruits Pyk2 to postsynaptic sites but the basis of Graf1c localization to those sites will require further study. Fyn kinase functions synergistically with Pyk2 and also localizes at postsynaptic sites (Um et al., 2012, 2013; Kaufman et al., 2015; Haas et al., 2016; Li and Götz, 2018). These data place Pyk2 at the center of postsynaptic signaling complex that controls dendritic spine morphology.

Graf1c links Pyk2 function to RhoA GTPase activity. The GTP-bound active RhoA is known to inhibit axonal and den- 
dritic growth, to cause dendritic spine retraction and to titrate synaptic plasticity (Jin and Strittmatter, 1997; Tashiro et al., 2000; Rex et al., 2009; Murakoshi et al., 2011). The presence of kinase active Pyk2 but not inactive Pyk2 limits the activity of Graflc to terminate RhoA activity by stimulating the GTPase. Consistent with a central role for Pyk 2 in synaptic $A D$ related signaling, $A \beta o$ and $\mathrm{AD}$ transgenes also increase RhoA activation. The ability of Pyk2 overexpression and $\mathrm{A} \beta \mathrm{o}$ stimulation to activate RhoA are consistent with Pyk2/Graf1c complex acting via this mechanism. Neuronal stimulation has been shown to increase active RhoA association with class I mGluRs (Schubert et al., 2006), which are upstream of Fyn/Pyk2 in the $\mathrm{A} \beta \mathrm{o} / \mathrm{PrP}^{\mathrm{C}}$ signaling cascade (Um et al., 2013; Haas et al., 2016). Others have observed RhoA activation in $\mathrm{AD}$ or $\mathrm{AD}$ model systems (Petratos et al., 2008; Huesa et al., 2010; Chacon et al., 2011; Herskowitz et al., 2013; Pozueta et al., 2013; Yang et al., 2013; Bolognin et al., 2014; Chang et al., 2015; Henderson et al., 2016), consistent with this mechanism.

Pyk2 is a tyrosine kinase capable of auto-phosphorylation and Graf1c phosphorylation. Although Graf1c interaction occurs via the isolated PRD domain of Pyk2, the regulation of Graflc and RhoA-GTP requires Pyk2 kinase activity. It is likely that both Pyk2 auto-phosphorylation and activation by Fyn contribute to Pyk2 regulation of Graf1c. Although our data show that Graf1c and RhoA play an essential role, additional kinase substrates of Pyk 2 may contribute to the ability of Pyk 2 and $A \beta o$ to induce loss of dendritic spines.

We have previously observed Pyk 2 activation in the transgenic APPswe/PS1 $\Delta$ E9 Alzheimer model, in parallel with A $\beta$ accumulation, synapse loss, and memory impairment (Kaufman et al., 2015; Haas et al., 2016, 2017). In such studies, genetic or pharmacological targeting of the $\mathrm{PrP}^{\mathrm{C}} / \mathrm{mGluR} 5 /$ Fyn pathway normalized Pyk2 activation, suggesting that Pyk2 is downstream of mGluR 5 and Fyn activation by A $\beta$ oligomers. Indeed, Pyk 2 physically associates with mGluR5 complexes in brain tissue (Haas et al., 2016). Recently, we demonstrated that Pyk2 is required for memory impairment and synapse density loss in APPswe/ PS1 $\Delta$ E9 mice (Salazar et al., 2018). Here, we delineate a downstream mechanism for the biochemical and dendritic morphology changes requiring Pyk2 function in neurons. Without Pyk2, cultured neurons are protected from $\mathrm{A} \beta \mathrm{O}$-induced reduction in dendritic spine motility and dendritic spine loss. This suggests that increased Pyk2 function enhances AD risk and is consistent with the observation that the AD risk SNP exhibits elevated Pyk2 expression in blood (Chan et al., 2015). Very recently, decreased pY402-Pyk2 was reported in 5XFAD transgenic mice, and viral Pyk2 overexpression reduced behavioral deficits in that strain (Giralt et al., 2018), opposite to the previous APP/PS1 studies and the prediction from the cellular studies here. The basis for these disparate findings is not clear, but the onset of 5XFAD phenotypes at juvenile or early adult stages, as opposed to late adult onset for APPswe/PS1 $\Delta \mathrm{E} 9$ mice may be relevant. Obviously, onset and progression of phenotypes during aging is more consistent with the human AD condition. Separately from AD models, Pyk2-null synaptic phenotypes reported for young mice (Giralt et al., 2017) resolve with age (Salazar et al., 2018). In this setting, the APP/PS1 may test Pyk2 effects after any development phenotypes have resolved. In addition, it should be noted that both of these transgenic lines overexpress familial AD mutant proteins, such that future testing of Pyk2 genotype effects in APP mutant knock-in mice (Saito et al., 2014) may be informative.

The role of Pyk2 in AD is likely to include an influence of Tau pathology, as well as $A \beta$-triggered neuronal dysfunction, based on phenotypic analysis in Drosophila (Dourlen et al., 2017) and biochemical interaction studies (Li and Götz, 2018). Furthermore, Pyk 2 and Tau both interact with Fyn, and Pyk2 activates the Tau kinase Gsk3 $\beta$ (Dikic et al., 1996; Hartigan et al., 2001; Sayas et al., 2006; Ittner et al., 2010; Usardi et al., 2011). Thus, Pyk2 may be juxtaposed to link and modulate the two major pathologies of AD through both microtubule and actin cytoskeletal elements. The biochemical analysis here demonstrates that Pyk2 activity couples to a postsynaptic signaling pathway for synapse loss via RhoA and F-actin that is central to brain dysfunction in $\mathrm{AD}$.

\section{References}

Alzheimer's Association (2012) 2012 Alzheimer's disease facts and figures. Alzheimers Dement 8:131-168.

Andreev J, Galisteo ML, Kranenburg O, Logan SK, Chiu ES, Okigaki M, Cary LA, Moolenaar WH, Schlessinger J (2001) Src and Pyk2 mediate G-protein-coupled receptor activation of epidermal growth factor receptor (EGFR) but are not required for coupling to the mitogen-activated protein (MAP) kinase signaling cascade. J Biol Chem 276:20130-20135.

Bartos JA, Ulrich JD, Li H, Beazely MA, Chen Y, Macdonald JF, Hell JW (2010) Postsynaptic clustering and activation of Pyk2 by PSD-95. J Neurosci 30:449-463.

Bito H, Furuyashiki T, Ishihara H, Shibasaki Y, Ohashi K, Mizuno K, Maekawa M, Ishizaki T, Narumiya S (2000) A critical role for a rhoassociated kinase, p160ROCK, in determining axon outgrowth in mammalian CNS neurons. Neuron 26:431-441

Bolognin S, Lorenzetto E, Diana G, Buffelli M (2014) The potential role of rho GTPases in Alzheimer's disease pathogenesis. Mol Neurobiol 50:406422.

Chacon PJ, Garcia-Mejias R, Rodriguez-Tebar A (2011) Inhibition of RhoA GTPase and the subsequent activation of PTP1B protects cultured hippocampal neurons against amyloid beta toxicity. Mol Neurodegener 6:14.

Chan G, White CC, Winn PA, Cimpean M, Replogle JM, Glick LR, Cuerdon NE, Ryan KJ, Johnson KA, Schneider JA, Bennett DA, Chibnik LB, Sperling RA, Bradshaw EM, De Jager PL (2015) CD33 modulates TREM2: convergence of Alzheimer loci. Nat Neurosci 18:1556-1558.

Chang RY, Etheridge N, Nouwens AS, Dodd PR (2015) SWATH analysis of the synaptic proteome in Alzheimer's disease. Neurochem Int 87:1-12.

Chang S, De Camilli P (2001) Glutamate regulates actin-based motility in axonal filopodia. Nat Neurosci 4:787-793.

Collins M, Bartelt RR, Houtman JC (2010a) T cell receptor activation leads to two distinct phases of Pyk2 activation and actin cytoskeletal rearrangement in human T cells. Mol Immunol 47:1665-1674.

Collins M, Tremblay M, Chapman N, Curtiss M, Rothman PB, Houtman JC (2010b) The T cell receptor-mediated phosphorylation of Pyk 2 tyrosines 402 and 580 occurs via a distinct mechanism than other receptor systems. J Leukocyte Biol 87:691-701.

Cooper JA (1987) Effects of cytochalasin and phalloidin on actin. J Cell Biol 105:1473-1478.

Dikic I, Tokiwa G, Lev S, Courtneidge SA, Schlessinger J (1996) A role for Pyk2 and src in linking G-protein-coupled receptors with MAP kinase activation. Nature 383:547-550.

Doherty GJ, Åhlund MK, Howes MT, Morén B, Parton RG, McMahon HT, Lundmark R (2011) The endocytic protein GRAF1 is directed to cellmatrix adhesion sites and regulates cell spreading. Mol Biol Cell 22:43804389.

Dourlen P, Fernandez-Gomez FJ, Dupont C, Grenier-Boley B, Bellenguez C, Obriot H, Caillierez R, Sottejeau Y, Chapuis J, Bretteville A, Abdelfettah F, Delay C, Malmanche N, Soininen H, Hiltunen M, Galas MC, Amouyel P, Sergeant N, Buée L, Lambert JC, et al. (2017) Functional screening of Alzheimer risk loci identifies PTK2B as an in vivo modulator and early marker of tau pathology. Mol Psychiatry 22:874-883.

Fischer M, Kaech S, Knutti D, Matus A (1998) Rapid actin-based plasticity in dendritic spines. Neuron 20:847-854.

Gebbink MF, Kranenburg O, Poland M, van Horck FP, Houssa B, Moolenaar WH (1997) Identification of a novel, putative rho-specific GDP/GTP exchange factor and a RhoA-binding protein: control of neuronal morphology. J Cell Biol 137:1603-1613.

Gimbel DA, Nygaard HB, Coffey EE, Gunther EC, Laurén J, Gimbel ZA, 
Strittmatter SM (2010) Memory impairment in transgenic Alzheimer mice requires cellular prion protein. J Neurosci 30:6367-6374.

Giralt A, Brito V, Chevy Q, Simonnet C, Otsu Y, Cifuentes-Díaz C, de Pins B, Coura R, Alberch J, Ginés S, Poncer JC, Girault JA (2017) Pyk2 modulates hippocampal excitatory synapses and contributes to cognitive deficits in a Huntington's disease model. Nat Commun 8:15592.

Giralt A, de Pins B, Cifuentes-Díaz C, López-Molina L, Farah AT, Tible M, Deramecourt V, Arold ST, Ginés S, Hugon J, Girault JA (2018) PTK2B/ Pyk2 overexpression improves a mouse model of Alzheimer's disease. Exp Neurol 307:62-73.

Haas LT, Strittmatter SM (2016) Oligomers of amyloid $\beta$ prevent physiological activation of the cellular prion protein-metabotropic glutamate receptor 5 complex by glutamate in Alzheimer disease. J Biol Chem 291:17112-17121.

Haas LT, Salazar SV, Kostylev MA, Um JW, Kaufman AC, Strittmatter SM (2016) Metabotropic glutamate receptor 5 couples cellular prion protein to intracellular signalling in Alzheimer's disease. Brain 139:526-546.

Haas LT, Salazar SV, Smith LM, Zhao HR, Cox TO, Herber CS, Degnan AP, Balakrishnan A, Macor JE, Albright CF, Strittmatter SM (2017) Silent allosteric modulation of mGluR5 maintains glutamate signaling while rescuing Alzheimer's mouse phenotypes. Cell Rep 20:76-88.

Hartigan JA, Xiong WC, Johnson GV (2001) Glycogen synthase kinase 3 beta is tyrosine phosphorylated by PYK2. Biochem Biophys Res Commun 284:485-489.

Heiss JK, Barrett J, Yu Z, Haas LT, Kostylev MA, Strittmatter SM (2017) Early activation of experience-independent dendritic spine turnover in a mouse model of Alzheimer's disease. Cereb Cortex 27:3660-3674.

Henderson BW, Gentry EG, Rush T, Troncoso JC, Thambisetty M, Montine TJ, Herskowitz JH (2016) Rho-associated protein kinase 1 (ROCK1) is increased in Alzheimer's disease and ROCK1 depletion reduces amyloidbeta levels in brain. J Neurochem 138:525-531.

Herskowitz JH, Feng Y, Mattheyses AL, Hales CM, Higginbotham LA, Duong DM, Montine TJ, Troncoso JC, Thambisetty M, Seyfried NT, Levey AI, Lah JJ (2013) Pharmacologic inhibition of ROCK2 suppresses amyloid- $\beta$ production in an Alzheimer's disease mouse model. J Neurosci 33:19086-19098.

Hildebrand JD, Taylor JM, Parsons JT (1996) An SH3 domain-containing GTPase-activating protein for rho and Cdc42 associates with focal adhesion kinase. Mol Cell Biol 16:3169-3178.

Hong S, Beja-Glasser VF, Nfonoyim BM, Frouin A, Li S, Ramakrishnan S, Merry KM, Shi Q, Rosenthal A, Barres BA, Lemere CA, Selkoe DJ, Stevens B (2016) Complement and microglia mediate early synapse loss in Alzheimer mouse models. Science 352:712-716.

Hsin H, Kim MJ, Wang CF, Sheng M (2010) Proline-rich tyrosine kinase 2 regulates hippocampal long-term depression. J Neurosci 30:1198311993.

Huang Y, Lu W, Ali DW, Pelkey KA, Pitcher GM, Lu YM, Aoto H, Roder JC, Sasaki T, Salter MW, MacDonald JF (2001) CAKbeta/Pyk2 kinase is a signaling link for induction of long-term potentiation in CA1 hippocampus. Neuron 29:485-496.

Huesa G, Baltrons MA, Gómez-Ramos P, Morán A, García A, Hidalgo J, Francés S, Santpere G, Ferrer I, Galea E (2010) Altered distribution of RhoA in Alzheimer's disease and $\mathrm{A} \beta \mathrm{PP}$ overexpressing mice. J Alzheimers Dis 19:37-56.

Ittner LM, Ke YD, Delerue F, Bi M, Gladbach A, van Eersel J, Wölfing H, Chieng BC, Christie MJ, Napier IA, Eckert A, Staufenbiel M, Hardeman E, Götz J (2010) Dendritic function of tau mediates amyloid- $\beta$ toxicity in Alzheimer's disease mouse models. Cell 142:387-397.

Jankowsky JL, Xu G, Fromholt D, Gonzales V, Borchelt DR (2003) Environmental enrichment exacerbates amyloid plaque formation in a transgenic mouse model of Alzheimer disease. J Neuropathol Exp Neurol 62:12201227.

Jankowsky JL, Fadale DJ, Anderson J, Xu GM, Gonzales V, Jenkins NA, Copeland NG, Lee MK, Younkin LH, Wagner SL, Younkin SG, Borchelt DR (2004) Mutant presenilins specifically elevate the levels of the 42 residue $\beta$-amyloid peptide in vivo: evidence for augmentation of a 42 -specific gamma secretase. Hum Mol Genet 13:159-170.

Janus C, Flores AY, Xu G, Borchelt DR (2015) Behavioral abnormalities in APPSwe/PS1dE9 mouse model of AD-like pathology: comparative analysis across multiple behavioral domains. Neurobiol Aging 36:2519-2532.

Jin Z, Strittmatter SM (1997) Rac1 mediates collapsin-1-induced growth cone collapse. J Neurosci 17:6256-6263.
Kaufman AC, Salazar SV, Haas LT, Yang J, Kostylev MA, Jeng AT, Robinson SA, Gunther EC, van Dyck CH, Nygaard HB, Strittmatter SM (2015) Fyn inhibition rescues established memory and synapse loss in Alzheimer mice. Ann Neurol 77:953-971.

Kostylev MA, Kaufman AC, Nygaard HB, Patel P, Haas LT, Gunther EC, Vortmeyer A, Strittmatter SM (2015) Prion-protein-interacting amyloid- $\beta$ oligomers of high molecular weight are tightly correlated with memory impairment in multiple Alzheimer mouse models. J Biol Chem 290:17415-17438.

Kostylev MA, Tuttle MD, Lee S, Klein LE, Takahashi H, Cox TO, Gunther EC, Zilm KW, Strittmatter SM (2018) Liquid and hydrogel phases of $\operatorname{PrP}^{\mathrm{C}}$ linked to conformation shifts and triggered by Alzheimer's amyloid- $\beta$ oligomers. Mol Cell 72:426-443.e412.

Lambert JC, Ibrahim-Verbaas CA, Harold D, Naj AC, Sims R, Bellenguez C, DeStafano AL, Bis JC, Beecham GW, Grenier-Boley B, Russo G, ThortonWells TA, Jones N, Smith AV, Chouraki V, Thomas C, Ikram MA, Zelenika D, Vardarajan BN, Kamatani Y, et al. (2013) Meta-analysis of 74,046 individuals identifies 11 new susceptibility loci for Alzheimer's disease. Nat Genet 45:1452-1458.

Laurén J, Gimbel DA, Nygaard HB, Gilbert JW, Strittmatter SM (2009) Cellular prion protein mediates impairment of synaptic plasticity by amyloid-beta oligomers. Nature 457:1128-1132.

Li C, Götz J (2018) Pyk2 is a novel tau tyrosine kinase that is regulated by the tyrosine kinase Fyn. J Alzheimers Dis 64:205-221.

Lucken-Ardjomande Häsler S, Vallis Y, Jolin HE, McKenzie AN, McMahon HT (2014) GRAF1a is a brain-specific protein that promotes lipid droplet clustering and growth, and is enriched at lipid droplet junctions. J Cell Sci 127:4602-4619.

Lundmark R, Doherty GJ, Howes MT, Cortese K, Vallis Y, Parton RG, McMahon HT (2008) The GTPase-activating protein GRAF1 regulates the CLIC/GEEC endocytic pathway. Curr Biol 18:1802-1808.

Menegon A, Burgaya F, Baudot P, Dunlap DD, Girault JA, Valtorta F (1999) FAK + and PYK2/CAKbeta, two related tyrosine kinases highly expressed in the central nervous system: similarities and differences in the expression pattern. Eur J Neurosci 11:3777-3788.

Mitra SK, Hanson DA, Schlaepfer DD (2005) Focal adhesion kinase: in command and control of cell motility. Nat Rev Mol Cell Biol 6:56-68.

Murakoshi H, Wang H, Yasuda R (2011) Local, persistent activation of rho GTPases during plasticity of single dendritic spines. Nature 472:100-104.

Newell-Litwa KA, Badoual M, Asmussen H, Patel H, Whitmore L, Horwitz AR (2015) ROCK1 and 2 differentially regulate actomyosin organization to drive cell and synaptic polarity. J Cell Biol 210:225-242.

Ohba T, Ishino M, Aoto H, Sasaki T (1998) Interaction of two proline-rich sequences of cell adhesion kinase beta with $\mathrm{SH} 3$ domains of p130Casrelated proteins and a GTPase-activating protein, Graf. Biochem J 330: $1249-1254$

Okigaki M, Davis C, Falasca M, Harroch S, Felsenfeld DP, Sheetz MP, Schlessinger J (2003) Pyk2 regulates multiple signaling events crucial for macrophage morphology and migration. Proc Natl Acad Sci U S A 100: $10740-10745$.

Park HJ, Westin CF, Kubicki M, Maier SE, Niznikiewicz M, Baer A, Frumin M, Kikinis R, Jolesz FA, McCarley RW, Shenton ME (2004) White matter hemisphere asymmetries in healthy subjects and in schizophrenia: a diffusion tensor MRI study. Neuroimage 23:213-223.

Park SY, Avraham HK, Avraham S (2004) RAFTK/Pyk2 activation is mediated by trans-acting autophosphorylation in a src-independent manner. J Biol Chem 279:33315-33322.

Petratos S, Li QX, George AJ, Hou X, Kerr ML, Unabia SE, Hatzinisiriou I, Maksel D, Aguilar MI, Small DH (2008) The $\beta$-amyloid protein of Alzheimer's disease increases neuronal CRMP-2 phosphorylation by a rhoGTP mechanism. Brain 131:90-108.

Pozueta J, Lefort R, Ribe EM, Troy CM, Arancio O, Shelanski M (2013) Caspase-2 is required for dendritic spine and behavioural alterations in J20 APP transgenic mice. Nat Commun 4:1939.

Purro SA, Nicoll AJ, Collinge J (2018) Prion protein as a toxic acceptor of amyloid- $\beta$ oligomers. Biol Psychiatry 83:358 -368.

Qian D, Lev S, van Oers NS, Dikic I, Schlessinger J, Weiss A (1997) Tyrosine phosphorylation of Pyk2 is selectively regulated by Fyn during TCR signaling. J Exp Med 185:1253-1259.

Rex CS, Chen LY, Sharma A, Liu J, Babayan AH, Gall CM, Lynch G (2009) Different rho GTPase-dependent signaling pathways initiate sequential 
steps in the consolidation of long-term potentiation. J Cell Biol 186:85-97.

Saito T, Matsuba Y, Mihira N, Takano J, Nilsson P, Itohara S, Iwata N, Saido TC (2014) Single app knock-in mouse models of Alzheimer's disease. Nat Neurosci 17:661-663.

Salazar SV, Strittmatter SM (2017) Cellular prion protein as a receptor for amyloid- $\beta$ oligomers in Alzheimer's disease. Biochem Biophys Res Commun 483:1143-1147.

Salazar SV, Cox TO, Lee S, Brody AH, Chyung AS, Haas LT, Strittmatter SM (2018) Alzheimer's disease risk factor Pyk2 mediates amyloid- $\beta$-induced synaptic dysfunction and loss. J Neurosci. Advance online publication. Retrieved December 5, 2018. doi: 10.1523/JNEUROSCI.1873-18.2018.

Sayas CL, Ariaens A, Ponsioen B, Moolenaar WH (2006) GSK-3 is activated by the tyrosine kinase Pyk2 during LPA1-mediated neurite retraction. Mol Biol Cell 17:1834-1844.

Schubert V, Da Silva JS, Dotti CG (2006) Localized recruitment and activation of RhoA underlies dendritic spine morphology in a glutamate receptor-dependent manner. J Cell Biol 172:453-467.

Swanger SA, Yao X, Gross C, Bassell GJ (2011) Automated 4D analysis of dendritic spine morphology: applications to stimulus-induced spine remodeling and pharmacological rescue in a disease model. Mol Brain 4:38.

Tashiro A, Minden A, Yuste R (2000) Regulation of dendritic spine morphology by the rho family of small GTPases: antagonistic roles of Rac and Rho. Cereb Cortex 10:927-938.

Taylor JM, Hildebrand JD, Mack CP, Cox ME, Parsons JT (1998) Characterization of Graf, the GTPase-activating protein for rho associated with focal adhesion kinase: phosphorylation and possible regulation by mitogen-activated protein kinase. J Biol Chem 273:8063-8070.
Taylor JM, Macklem MM, Parsons JT (1999) Cytoskeletal changes induced by GRAF, the GTPase regulator associated with focal adhesion kinase, are mediated by Rho. J Cell Sci 112:231-242.

Tse KW, Lin KB, Dang-Lawson M, Guzman-Perez A, Aspnes GE, Buckbinder L, Gold MR (2012) Small molecule inhibitors of the Pyk2 and FAK kinases modulate chemoattractant-induced migration, adhesion and Akt activation in follicular and marginal zone B cells. Cell Immunol 275:47-54.

Um JW, Nygaard HB, Heiss JK, Kostylev MA, Stagi M, Vortmeyer A, Wisniewski T, Gunther EC, Strittmatter SM (2012) Alzheimer amyloid- $\beta$ oligomer bound to postsynaptic prion protein activates Fyn to impair neurons. Nat Neurosci 15:1227-1235.

Um JW, Kaufman AC, Kostylev M, Heiss JK, Stagi M, Takahashi H, Kerrisk ME, Vortmeyer A, Wisniewski T, Koleske AJ, Gunther EC, Nygaard HB, Strittmatter SM (2013) Metabotropic glutamate receptor 5 is a coreceptor for Alzheimer $\mathrm{A} \beta$ oligomer bound to cellular prion protein. Neuron 79:887-902.

Usardi A, Pooler AM, Seereeram A, Reynolds CH, Derkinderen P, Anderton B, Hanger DP, Noble W, Williamson R (2011) Tyrosine phosphorylation of tau regulates its interactions with Fyn SH2 domains, but not SH3 domains, altering the cellular localization of tau. FEBS J 278:2927-2937.

Yang H, Wittnam JL, Zubarev RA, Bayer TA (2013) Shotgun brain proteomics reveals early molecular signature in presymptomatic mouse model of Alzheimer's disease. J Alzheimers Dis 37:297-308.

Zhang C, Lambert MP, Bunch C, Barber K, Wade WS, Krafft GA, Klein WL (1994) Focal adhesion kinase expressed by nerve cell lines shows increased tyrosine phosphorylation in response to Alzheimer's A $\beta$ peptide. J Biol Chem 269:25247-25250. 